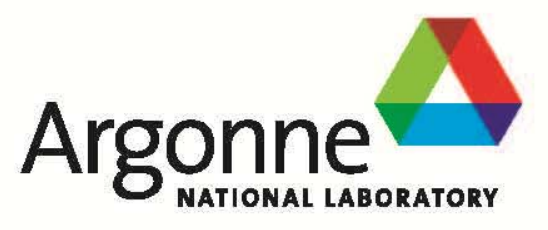

\title{
Development of Solvent Extraction Approach to Recycle Enriched Molybdenum Material
}

Nuclear Engineering Division 


\begin{abstract}
About Argonne National Laboratory
Argonne is a U.S. Department of Energy laboratory managed by UChicago Argonne, LLC under contract DE-AC02-06CH11357. The Laboratory's main facility is outside Chicago, at 9700 South Cass Avenue, Argonne, Illinois 60439. For information about Argonne

and its pioneering science and technology programs, see www.anl.gov.
\end{abstract}

\title{
DOCUMENT AVAILABILITY
}

Online Access: U.S. Department of Energy (DOE) reports produced after 1991 and a growing number of pre-1991 documents are available free via DOE's SciTech Connect (http://Www.osti.gov/scitech/).

Reports not in digital format may be purchased by the public from the National Technical Information Service (NTIS):

U.S. Department of Commerce

National Technical Information Service

5301 Shawnee Rd

Alexandria, VA 22312

unw.ntis.gov

Phone: (800) 553-NTIS (6847) or (703) 605-6000

Fax: (703) 605-6900

Email: orders@ntis.gov

Reports not in digital format are available to DOE and DOE contractors from the Office of Scientific and Technical Information (OST):

U.S. Department of Energy

Office of Scientific and Technical Information

P.O. Box 62

Oak Ridge, TN 37831-0062

unw.osti.gov

Phone: (865) 576-8401

Fax: (865) 576-5728

Email: reports@osti.gov

\section{Disclaimer}

This report was prepared as an account of work sponsored by an agency of the United States Government. Neither the United States Government nor any agency thereof, nor UChicago Argonne, LLC, nor any of their employees or officers, makes any warranty, express or implied, or assumes any legal liability or responsibility for the accuracy, completeness, or usefulness of any information, apparatus, product, or process disclosed, or represents that its use would not infringe privately owned rights. Reference herein to any specific commercial product, process, or service by trade name, trademark, manufacturer, or otherwise, does not necessarily constitute or imply its endorsement, recommendation, or favoring by the United States Government or any agency thereof. The views and opinions of document authors expressed herein do not necessarily state or reflect those of the United States Government or any agency thereof. 


\section{Development of Solvent Extraction Approach to Recycle Enriched Molybdenum Material}

by

Peter Tkac, ${ }^{1}$ M. Alex Brown, ${ }^{1}$ Sujat Sen, ${ }^{2}$ Delbert L. Bowers, ${ }^{1}$ Kent Wardle, ${ }^{1}$

Jacqueline M. Copple, ${ }^{1}$ Krzysztof Z. Pupek, ${ }^{1}$ Trevor L. Dzwiniel, ${ }^{2}$ Candido Pereira,${ }^{1}$

Gregory K. Krumdick, ${ }^{2}$ and George F. Vandegrift ${ }^{1}$

${ }^{1}$ Nuclear Engineering Division, Argonne National Laboratory

'Energy Systems Division, Argonne National Laboratory

June 2016 



\section{CONTENTS}

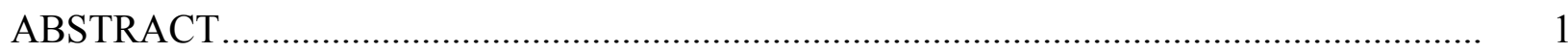

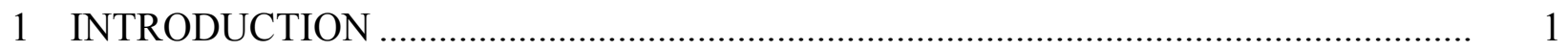

2 SOLVENT EXTRACTION - BATCH EXPERIMENTS .................................................... 2

$2.1 \quad$ Batch Studies with TCE as Diluent ......................................................................... 2

2.1.1 Distribution Ratios ...................................................................................... 3

2.1.2 Dispersion Numbers..................................................................................... 4

2.1.3 X-ray Absorption Fine Structure ………………….................................. 5

2.1.4 $\mathrm{H} / \mathrm{KCl}$ Extraction ................................................................................... 7

2.1.5 Extraction Behavior of $\mathrm{Zr}$ and $\mathrm{Nb}$....................................................... 8

2.2 Batch Studies with 1-Octanol as Diluent ................................................................... 8

2.2.1 Extraction of $\mathrm{HCl}$ by $50 \%$ TBP in 1-Octanol ............................................. 8

2.2.2 Extraction of Mo by 50\% TBP in 1-Octanol ............................................. 10

2.2.3 Stripping of Mo from TBP....................................................................... 13

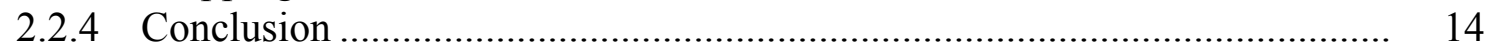

2.4 Material Compatibility and Contactor Hydraulic Testing ……................................ 15

2.4.1 Density Measurements and Dispersion Testing............................................ 15

2.4.2 Immersion Tests................................................................................ 16

2.4.3 Single-Stage 2-cm Contactor Hydraulic Testing ....................................... 16

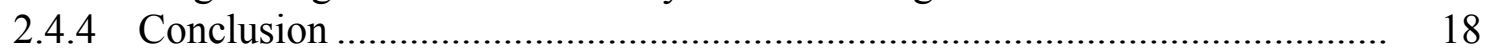

3 METHODS TO REMOVE $\mathrm{NH}_{4} \mathrm{Cl}$ FROM THE SOLVENT EXTRACTION

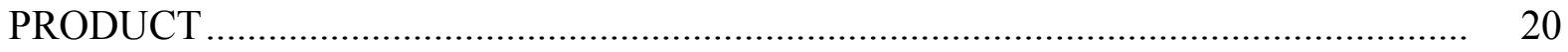

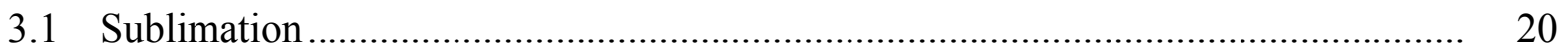

3.2 Precipitation of Molybdenum Using Acetic Acid ................................................. 21

3.3 Removal of $\mathrm{NH}_{4} \mathrm{Cl}$ Using Differential Solubility .................................................. 22

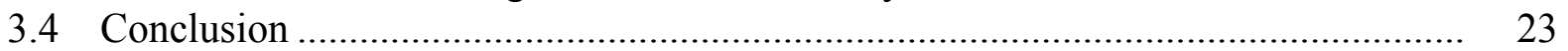

4 LARGE-SCALE RECYCLE PROCESS USING SOLVENT EXTRACTION.................. 25

5 PROCESS FOR PARTICLE SIZE CONTROL OF MOLYBDENUM OXIDE ……….... 29

5.1 Particle-Size Dependence of $\mathrm{MoO}_{3}$ on Recycled $\left(\mathrm{NH}_{4}\right)_{6} \mathrm{Mo}_{7} \mathrm{O}_{24}$ Powder................ 29

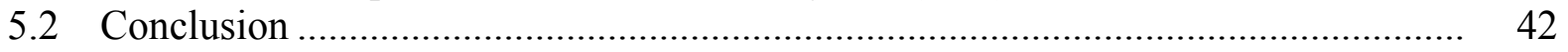

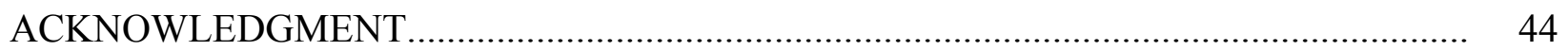

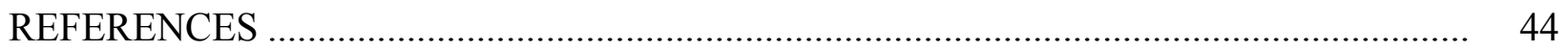




\section{FIGURES}

1 D Values into $30 \% \mathrm{TBP} / \mathrm{TCE}$ as a Function of $\mathrm{HCl}$ with Trace Mo........................... 3

2 D Values into $30 \% \mathrm{TBP} / \mathrm{TCE}$ as a Function of $\mathrm{HCl}$ and $[\mathrm{Mo}]_{\mathrm{T}}=70 \mathrm{mM} \ldots \ldots \ldots \ldots \ldots \ldots \ldots . . .4$

3 D Values as a Function of $[\mathrm{Mo}]_{\mathrm{T}}$ into $30 \% \mathrm{TBP} / \mathrm{TCE}$ from $5 \mathrm{M} \mathrm{HCl}+0.5 \mathrm{M} \mathrm{K}^{+} \ldots \ldots$.

$4 \quad k^{3}$-Weighted Fourier-Transform XAFS of Mo in $1.2 \mathrm{M} \mathrm{HCl}, 5 \mathrm{M} \mathrm{HCl}$, and $30 \%$ TBP

$7 \quad$ Extraction of ${ }^{99} \mathrm{Mo}$ and ${ }^{95} \mathrm{Nb}$ by $30 \% \mathrm{TBP} / \mathrm{TCE}$ as a Function of $\mathrm{HCl}$....................... 7

$8 \quad$ Extraction of $\mathrm{HCl}$ by $50 \%$ TBP in 1-Octanol ....................................................... 9

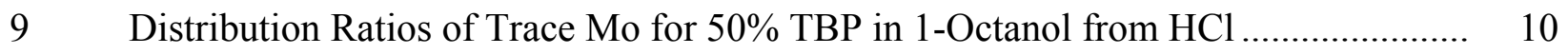

10 Photograph of Organic and Aqueous Phases after Extraction from 0.1 M Mo in 1,

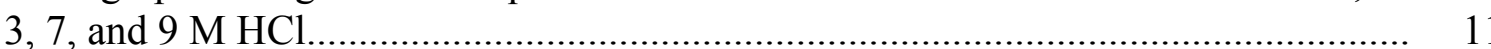

11 Saturated Concentration of K after Dilution of Spent Generator Surrogate Solution with $\mathrm{HCl}$....................................................................................... 13

12 Flowsheet of Mo Recovery Process Using Solvent Extraction with TBP .................... 15

13 Snapshot of Printed ANL 2-cm Centrifugal Contactor................................................ 17

14 Small-Scale Apparatus Used for Sublimation of $\mathrm{NH}_{4} \mathrm{Cl}$ from Solid Mixture of

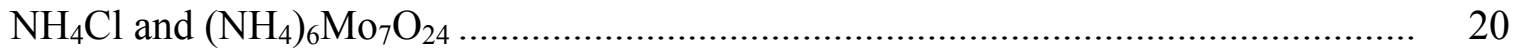

15 Large-Scale Sublimation Apparatus for Separation of $\mathrm{NH}_{4} \mathrm{Cl}$ from $\left(\mathrm{NH}_{4}\right)_{6} \mathrm{Mo}_{7} \mathrm{O}_{24}$ after Solvent Extraction Using TBP

16 Photographs of White Mo Solid Obtained after Precipitation with AcA and $\mathrm{MoO}_{3}$ Product Obtained after Heating at $500^{\circ} \mathrm{C}$

17 Photographs of Ammonium Molybdate Obtained after Wash with Ethanol-Water Mixture and $\mathrm{MoO}_{3}$ Product Obtained after Heating at $500^{\circ} \mathrm{C}$

18 SEM Images of Ammonium Molybdate Recycled from Solvent Extraction Process, Molybdenum Trioxide Obtained after Decomposition of Molybdate at $500^{\circ} \mathrm{C}$, and Molybdenum Trioxide Obtained after Heating at $650^{\circ} \mathrm{C}$

19 Funnel Used for Separation of Mo from Solution 


\section{FIGURES (Cont.)}

20 Mixture of $\mathrm{NH}_{4} \mathrm{Cl}$ and $\left(\mathrm{NH}_{4}\right)_{6} \mathrm{Mo}_{7} \mathrm{O}_{24} \cdot \mathrm{xH}_{2} \mathrm{O}$ after Evaporation of $\mathrm{NH}_{4} \mathrm{OH}$ from Mo Strip Solution

21 SEM Images of Ammonium Molybdate Crystals as Received from Supplier (Sample 1, Sigma).

22 TGA of Ammonium Molybdate Crystals as Received from Supplier (Sample 1), DSC Analysis during Same Test, and (c) Overlay of DSC and TGA

23 SEM Images of Calcined Powder after TGA Test (Sample 1, Sigma)

24 SEM Images of Ammonium Molybdate Crystals as Received from Supplier (Sample 2, Acros)

25 TGA of Ammonium Molybdate Crystals as Received from Supplier (Sample 2) and DSC Analysis during Same Test.

26 SEM Images of Calcined Powder after TGA Test (Sample 2, Acros)

27 SEM Images of Ammonium Molybdate Crystals as Received from Supplier (Sample 3, Alfa)

28 TGA of Ammonium Molybdate Crystals as Received from Supplier (Sample 3) and DSC Analysis during Same Test.

29 SEM Images of Calcined Powder after TGA Test (Sample 3, Alfa).....

30 SEM Images of Ammonium Molybdate Crystals Recycled from Solvent Extraction Process (Sample 4, NE)

31 TGA of Ammonium Molybdate Crystals as Received and Recycled from Solvent

Extraction Process (Sample 4-NE) and DSC Analysis during Same Test.

32 SEM Images of Calcined Recycled Powder from Solvent Extraction Process after TGA Test (Sample 4-NE).

33 SEM Images of Molybdenum Oxide Crystals as Received (Sample 5, Alfa)

34 TGA of Ammonium Heptamolybdate Crystals (Samples 1-4) as Received from Various Suppliers and DSC Analysis during Same Test 


\section{FIGURES (Cont.)}

35 SEM Images of Sample 1 (Sigma) after Calcination at $500^{\circ} \mathrm{C}$ for 30 Minutes........... 41

36 SEM Images of Sample 5 after Calcination at $500^{\circ} \mathrm{C}$ for 1 Hour.............................. 42

\section{TABLES}

$1 \quad$ Dispersion Numbers for Various TBP Systems...............................................

2 Results from $k^{3}$-Weighted Fourier-Transform XAFS Fits of Mo in $1.2 \mathrm{M} \mathrm{HCl,} 5$ $\mathrm{M} \mathrm{HCl}$, and $30 \% \mathrm{TBP}$....

3 The Effect of $30 \% \mathrm{TBP} / \mathrm{TCE}$ Extraction on the Initial Concentrations of $\mathrm{HCl}$ and $\mathrm{K}^{+}$

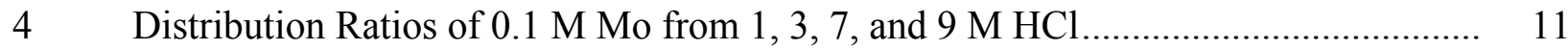

5 Extraction of High Mo Concentration after Dilution of Spent Generator Surrogate Solution with $\mathrm{HCl}$

6 Concentration of Mo and K Determined by ICP-MS after Dilution of Spent Mo Generator Surrogate Solution with $10.5 \mathrm{M} \mathrm{HCl}$

7 Relative Concentrations of Mo and $\mathrm{K}$ in Various Stages of the Extraction of $0.3 \mathrm{M}$ Mo from $5 \mathrm{M} \mathrm{HCl}$ Using 50\% TBP in 1-Octanol

8 Back-Extraction D(Mo) Values from 50\% TBP in 1-Octanol after Extraction of $\sim 0.3 \mathrm{M}$ Mo from 3-5 $\mathrm{M} \mathrm{HCl}$

9 Concentration of Various Elements in Different Stages of Solvent Extraction Process Using TBP

10 Calculated Values of Structural Parameters of AHM Calcined at Different Temperatures. 


\title{
DEVELOPMENT OF SOLVENT EXTRACTION APPROACH TO RECYCLE ENRICHED MOL YBDENUM MATERIAL
}

\begin{abstract}
Argonne National Laboratory, in cooperation with Oak Ridge National Laboratory and NorthStar Medical Technologies, LLC, is developing a recycling process for a solution containing valuable Mo-100 or Mo-98 enriched material. Previously, Argonne had developed a recycle process using a precipitation technique. However, this process is labor intensive and can lead to production of large volumes of highly corrosive waste. This report discusses an alternative process to recover enriched Mo in the form of ammonium heptamolybdate by using solvent extraction. Small-scale experiments determined the optimal conditions for effective extraction of high Mo concentrations. Methods were developed for removal of ammonium chloride from the molybdenum product of the solvent extraction process. In large-scale experiments, very good purification from potassium and other elements was observed with very high recovery yields $(\sim 98 \%)$.
\end{abstract}

\section{INTRODUCTION}

Argonne National Laboratory (Argonne), in cooperation with Oak Ridge National Laboratory (ORNL) and NorthStar Medical Technologies, LLC (NorthStar), is developing a recycling process for a solution containing valuable Mo-100 or Mo-98 enriched material produced from spent Mo-99/Tc-99m RadioGenix ${ }^{\text {TM }}$ generators. Previously, Argonne developed a recycle process using a precipitation technique, where spent generator solution containing a highly alkaline solution of $\mathrm{K}_{2} \mathrm{MoO}_{4}(0.2 \mathrm{~g}-\mathrm{Mo} / \mathrm{mL}$ in $5 \mathrm{M} \mathrm{KOH})$ is mixed with glacial acetic acid to precipitate the molybdenum [1-3]. The Mo precipitate is then further washed with concentrated nitric acid to remove potassium. After the final $\mathrm{HNO}_{3}$ wash, the precipitate in the form of $\mathrm{MoO}_{3} \cdot \mathrm{xH}_{2} \mathrm{O}$ is dried and dehydrated to form $\mathrm{MoO}_{3}$. Usual recoveries obtained are $\sim 95 \%$ with the concentration of potassium below $100 \mathrm{ppm}(100 \mathrm{mg}-\mathrm{K} / \mathrm{kg}-\mathrm{Mo})$. However, this process is labor intensive and can lead to production of large volumes of highly corrosive waste.

In this report we discuss an alternative process to recover enriched Mo using solvent extraction. The main advantage of this approach is very high decontamination factors from potassium in one extraction step, easy scalability, automation, and significantly lower waste stream generation. A high separation factor for Mo and $\mathrm{K}\left(\mathrm{SF}_{(\mathrm{Mo} / \mathrm{K})} \sim 1 \times 10^{4}\right)$ can be easily achieved by solvent extraction using tributyl phosphate [4]. Furthermore, the high Mo concentrations combined with the need for a high throughput preclude other treatment options, such as column chromatography or precipitation methods. 


\section{SOLVENT EXTRACTION - BATCH EXPERIMENTS}

Small-scale solvent extraction experiments were performed to determine the optimal conditions for effective extraction of high Mo concentrations. A solution of $50 \mathrm{vol} \%$ tributyl phosphate (1.83 M TBP) in 1-octanol or 30\% TBP (1.1 M) in tetrachloroethylene (TCE) was used as the solvent for all extraction experiments. Before use, the solvent was pre-equilibrated with an aqueous phase containing $\mathrm{HCl}$ in the same concentration as that used in the extraction experiment. Distribution ratios were measured in batch experiments. Samples were vigorously agitated in extraction vials using a vortex mixer at an organic/aqueous volume ratio of 1:1 under ambient temperature $\left(20^{\circ} \mathrm{C}\right)$. After agitation, the phases were separated by centrifugation, and aliquots from both the organic and aqueous phases were taken to measure the equilibrium concentrations of the metal using a NaI detector (Wizard with RiaCalc WIZ program 3.6 software, and energy discrimination of 700-900 keV) or HPGe (Ortec) detector.

Molybdenum-99 was provided from a TechneLite generator (Lantheus) that had been eluted with ammonium hydroxide. Distribution ratios for experiments performed without ${ }^{99}$ Mo tracers were determined by inductively coupled plasma-mass spectroscopy (ICP-MS). Large-scale experiments were performed with 50\% TBP in 1-octanol in $12 \mathrm{~L}$ high density polyethylene (HDPE) bottles, and phases were separated with a $5 \mathrm{~L}$ separatory funnel. The mean activity coefficients of $\mathrm{H}^{+}, \mathrm{Cl}^{-}$, and $\mathrm{H}_{2} \mathrm{O}$ were calculated by the method of Bromley [5].

Three diluents for TBP were investigated in this work: n-dodecane, 1-octanol, and tetrachloroethylene (TCE). It was observed that $30 \%$ TBP in dodecane formed a third phase at higher HCl/Mo loadings. Third phase formation occurs when the concentration of "aqueous species" exceeds the solubility limit in the organic phase, and the organic phase splits into two phases. This is not a desired behavior because it would complicate the recovery process. Therefore, we looked at replacing $n$-dodecane by a more polar diluent to avoid the formation of a third phase. More detailed work was performed with 30\% TBP in TCE and 50\% TBP in 1-octanol. There are both advantages and disadvantages to both of these diluents for future considerations. Namely, if this extraction system is scaled up and automated by using a bank of centrifugal contactors (due to the corrosive nature of $\mathrm{HCl}$, plastic 3-D printed contactors are the most viable option), the compatibility of various potential plastic materials with TBP, TCE, and octanol is very important. Because of the limited compatibility of chlorinated organic diluents, such as TCE, the octanol is in general a better option from chemical compatibility; however, as will be discussed in more detail later, TBP/octanol system extracts more $\mathrm{HCl}$ than the TBP/TCE system, lowering the effective concentration of TBP for Mo. Moreover, the difference in density between TBP/octanol and $\mathrm{NH}_{4} \mathrm{OH}$ during the strip stage is not sufficient for use in centrifugal contactors.

\subsection{BATCH STUDIES WITH TCE AS DILUENT}

Samples labeled "High-Mo" contained an acidified chloride solution of potassium molybdate that had been filtered using a Whatman $0.2-\mu \mathrm{m}$ syringe filter. The acid concentration of "high-Mo" stock was analyzed by potentiometry after the solution had been treated with pre- 
equilibrated (6 M HCl) 30\% TBP (TCE) and was determined to be 5.4 M. Potentiometry was performed with a Metrohm automated titrator and a Metrohm combination glass electrode.

\subsubsection{Distribution Ratios}

Distribution ratios of Mo (defined by Eq. 1) into 30\% TBP in TCE from $\mathrm{HCl}$ were investigated primarily as a function of molybdenum concentration [Mo].

$$
D_{M o}=\frac{\sum[M o]_{o r g}}{\sum[M o]_{a q}}
$$

Within the range of $0.1<\left\{C l^{-}\right\}<10$, the distribution of trace ${ }^{99}$ Mo exhibited a fourthorder dependence with extraction by $30 \%$ TBP /TCE (Figure 1). At higher activities of chloride $(>8)$, the distribution ratios still increased but at a much lower slope dependence on account of Mo-chloride complexation in the aqueous phase. As evident in Figure 2, the same trend was observed at higher concentrations of total Mo $\left([\mathrm{Mo}]_{\mathrm{T}}\right)$, but with slightly lower $\mathrm{D}$ values as a result of the free TBP concentration dropping due to being tied up by molybdenum in the organic phase. The results in Figure 3 also demonstrate the effects of high metal loading, as the D value considerably dropped past $100 \mathrm{mM}$ Mo concentrations.

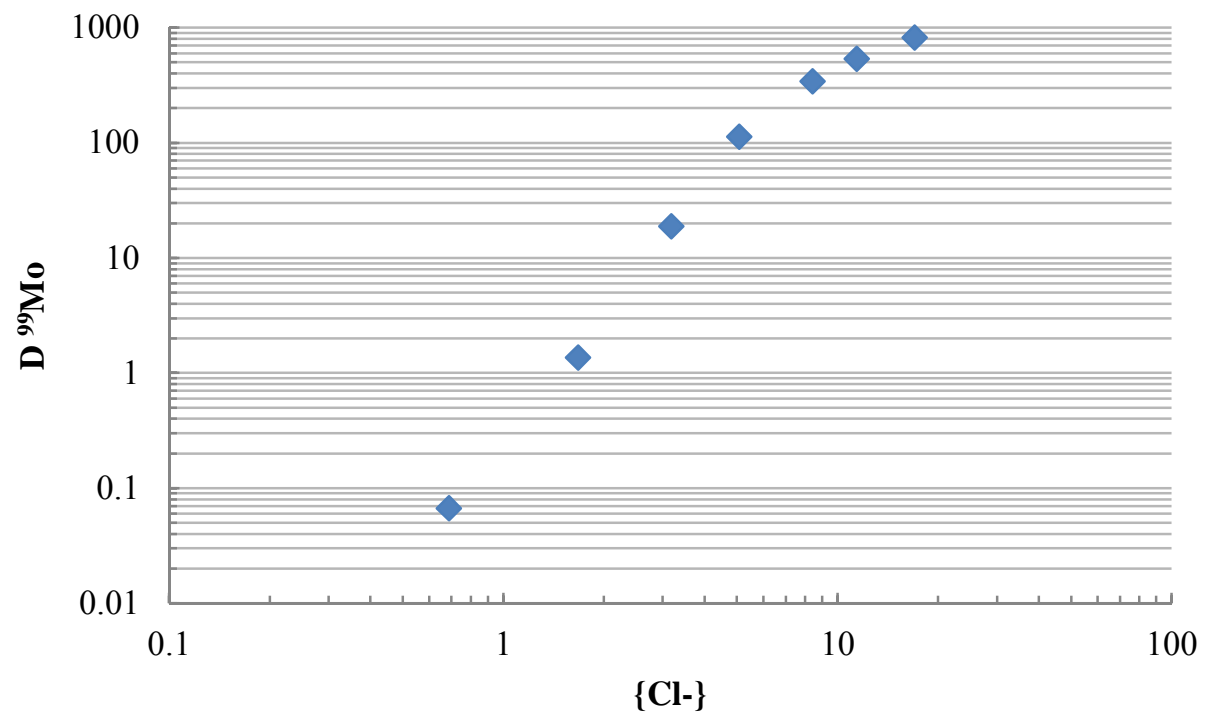

FIGURE 1 D Values into 30\% TBP/TCE as a Function of HCl with Trace Mo 


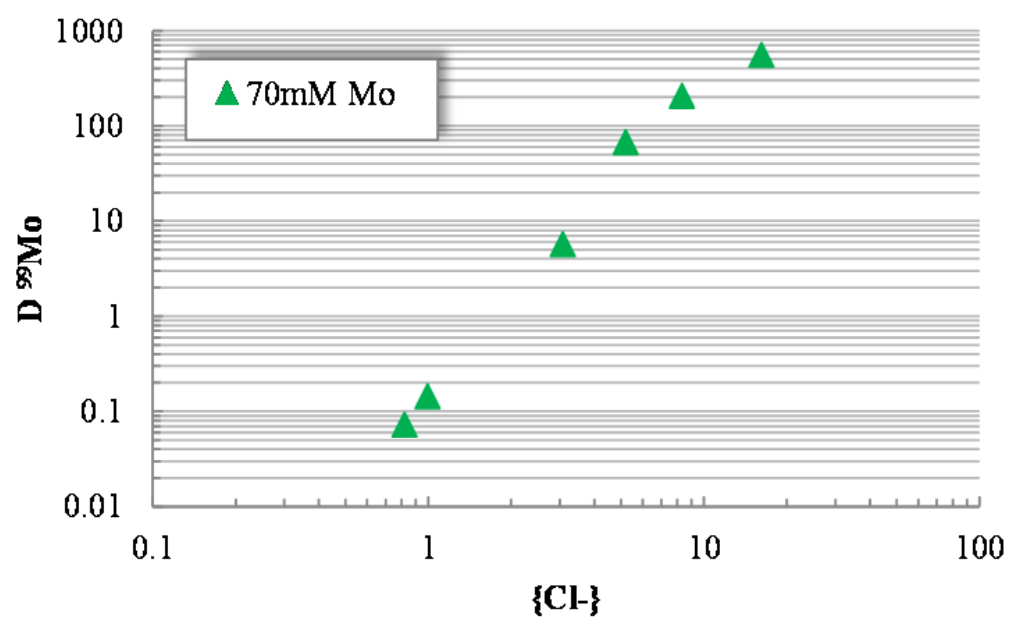

FIGURE 2 D Values into $30 \%$ TBP/TCE as a Function of $\mathrm{HCl}$ and $[\mathrm{Mo}]_{\mathrm{T}}=70 \mathrm{mM}$

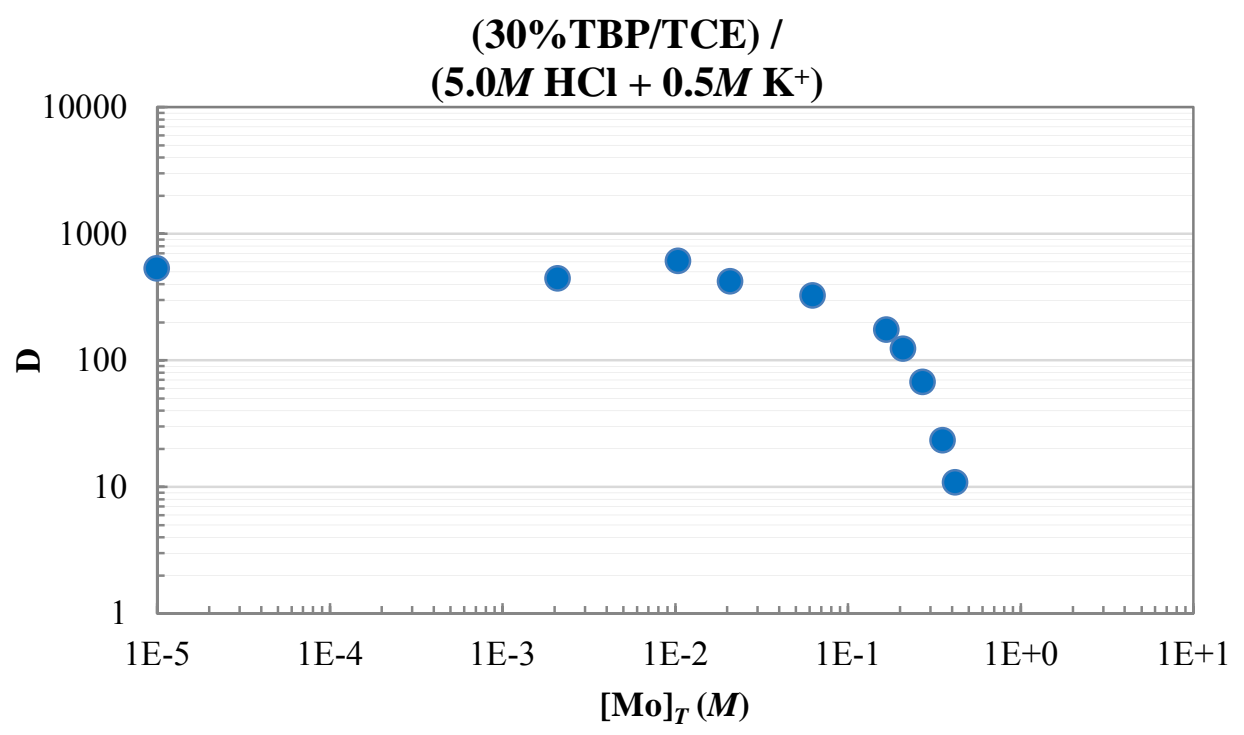

FIGURE 3 D Values as a Function of $\left[\mathrm{Mo}_{\mathrm{T}}\right.$ into $30 \%$ TBP/TCE from $5 \mathrm{M} \mathrm{HCl}+0.5 \mathrm{M} \mathrm{K}^{+}$

\subsubsection{Dispersion Numbers}

The quality of a solvent extraction process is in many ways dependent on the nature of the two immiscible phases and how they disengage from one another. Furthermore, the emulsion characteristics greatly impact the solvents' performance in countercurrent multi-stage centrifugal contactors; sluggish disengagement can result in phase carry-over and overall poor results. In this regard the disengagement properties between two immiscible solvents can be analyzed with a dimensionless dispersion number, which quantifies the disengagement speed. Dispersion 
numbers for pre-equilibrated $\mathrm{TBP}$ and $\mathrm{HCl}$ were determined according to the equation of Leonard [6]:

$$
N_{D i}=\frac{1}{t_{B}} \sqrt{\frac{\Delta Z}{g}}
$$

where $t_{B}$ is the average dispersion time $(\mathrm{s}), Z$ is the length of the testing cylinder $(200 \mathrm{~mm}$ for a $100 \mathrm{~mL}$ graduated), and $g$ is $9.81 \mathrm{~m} / \mathrm{s}^{2}$.

The results are listed in Table 1 . Dispersion values above $4 \times 10^{-4}$ are considered sufficient for stagewise solvent extraction equipment; values above $16 \times 10^{-4}$ are considered excellent. The $\mathrm{HCl} / \mathrm{TBP}$ systems disengaged quickly and cleanly. Dispersion numbers could not be calculated for systems involving ammonium hydroxide since the phases did not disengage. Reducing the concentration of ammonium hydroxide by ten-fold did not improve phase separation. The ammonium hydroxide was concentrated with $0.5 \mathrm{M} \mathrm{MoO}_{4}{ }^{2-}$, with the idea that increasing the ionic activity of the solution would improve performance. The phases disengaged slowly, requiring approximately $5 \mathrm{~min}$, which results in a dispersion number of about 1 (unacceptable according to Leonard [6]).

\section{TABLE 1 Dispersion Numbers for Various TBP Systems}

\begin{tabular}{llc}
\hline \multicolumn{1}{c}{ Organic Solvent } & \multicolumn{1}{c}{ Aqueous Solvent } & $N_{D i} \times 10^{-4}$ \\
\hline & & \\
$50 \%$ TBP in octanol & $5 \mathrm{M} \mathrm{HCl}$ & 27 \\
$30 \%$ TBP in TCE & $5 \mathrm{M} \mathrm{HCl}$ & 23 \\
$50 \%$ TBP in octanol & $20 \% \mathrm{NH}_{4} \mathrm{OH}$ & $\mathrm{ND}$ \\
$30 \%$ TBP in TCE & $20 \% \mathrm{NH}_{4} \mathrm{OH}$ & $\mathrm{ND}$ \\
$50 \%$ TBP in octanol & $2 \% \mathrm{NH}_{4} \mathrm{OH}$ & $\mathrm{ND}$ \\
$50 \%$ TBP in octanol & $2 \% \mathrm{NH}_{4} \mathrm{OH}+0.5 \mathrm{M} \mathrm{Mo}$ & 1 \\
\hline
\end{tabular}

ND signifies the dispersion number could not be determined.

\subsubsection{X-ray Absorption Fine Structure}

X-ray absorption fine structure (XAFS) spectroscopy is a powerful tool available at Argonne's Advanced Photon Source (APS). By probing the atom's core electrons via the photoelectric effect, nearly every element can be analyzed with respect to the local coordination environment. The results can provide a detailed description of the number and type of neighboring atoms, as well as extremely accurate bond distances. To characterize and understand Mo recovery by solvent extraction, we analyzed the organic and aqueous phases of the process by XAFS: Mo-TBP (30\%, n-dodecane), Mo in $1.2 \mathrm{M} \mathrm{HCl}$, and $\mathrm{Mo}$ in $5 \mathrm{M} \mathrm{HCl}$. 
Measurements were made on the insertion device beam line of the Materials Research Collaborative Access Team (MRCAT) at the APS. The X-ray energy was selected with a doublecrystal $\mathrm{Si}(111)$ monochromator that was liquid nitrogen cooled, and a platinum-coated mirror was used for harmonic rejection. Data were collected in transmission in step scan mode and modeled by using Athena and Artemis software [7].

Figure 4 displays the Fourier transform XAFS spectra of Mo in $1.2 \mathrm{M} \mathrm{HCl}, 5 \mathrm{M} \mathrm{HCl}$, and $30 \%$ TBP in $n$-dodecane (extracted from $5 \mathrm{M} \mathrm{HCl}$ solution), respectively. The spectrum of Mo in $1 \mathrm{M} \mathrm{HNO}_{3}$ is also shown for comparison (Figure 4). The blue curve represents the raw spectrum, the red curve represents the model fit. Table 2 lists the bond distances of the scatter potentials.

The spectra of Mo in $1.2 \mathrm{M} \mathrm{HCl}$ (Figure 4) strongly support the characteristics of the molybdenyl ion- $-\mathrm{MoO}_{2}{ }^{2+}$. The double-bonded oxygen distances from the metal center are in agreement with numerous crystallographic and XAFS studies [8]. The secondary Mo-O pathway is afforded to the outer-shell aqua cations of the 5-6 coordinate molybdenyl cation; the best fit to the data was obtained with three water ligands. No chloride interaction was observed.

The spectra for Mo in $5 \mathrm{M} \mathrm{HCl}$ (Figure 5) exhibited a new peak at about $2.3 \AA$, which can be assigned to a chloride complex with molybdenyl [8]. The best fit to the data was obtained by assigning two chloride ligands around the molybdenyl.

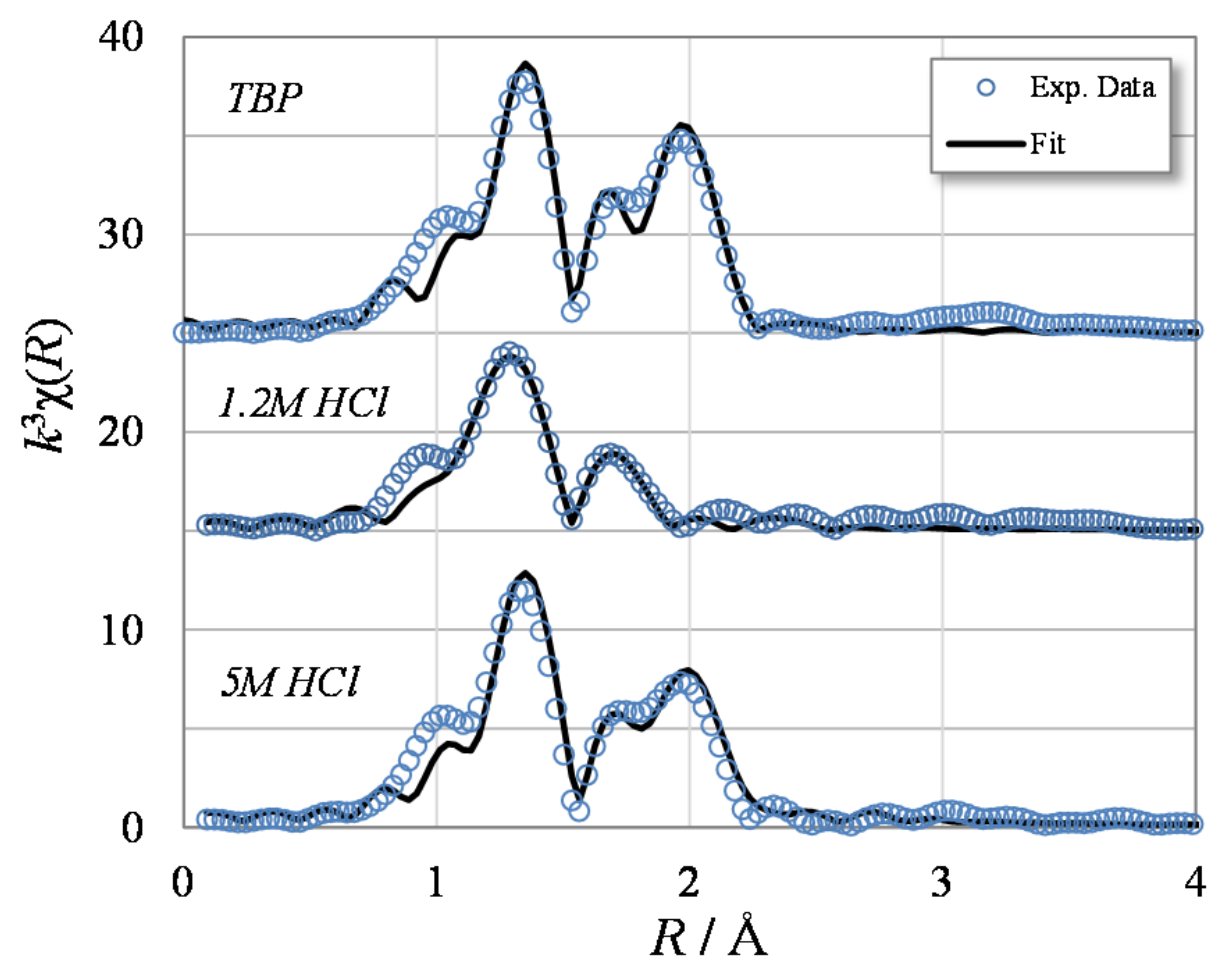

FIGURE $4 \boldsymbol{k}^{3}$-Weighted Fourier-Transform XAFS (uncorrected for phase shift) of Mo in $1.2 \mathrm{M} \mathrm{HCl}, 5 \mathrm{M} \mathrm{HCl}$, and $30 \%$ TBP (n-dodecane) 
TABLE 2 Results from $\boldsymbol{k}^{3}$-Weighted FourierTransform XAFS Fits of Mo in 1.2 M HCl, 5 M HCl, and $30 \%$ TBP; $S_{0}^{2}=0.8 ; N=$ Coordination Number

\begin{tabular}{lllc}
\hline & \multicolumn{3}{c}{ Bond Distance $(\AA)$} \\
\cline { 2 - 4 } Pathway & $1.2 \mathrm{M} \mathrm{HCl}$ & \multicolumn{3}{c}{$5 \mathrm{M} \mathrm{HCl}$} & $\mathrm{TBP}$ \\
\hline & & & \\
$\mathrm{Mo}=\mathrm{O}$ & $1.69(N=2)$ & $1.69(N=2)$ & $1.69(N=2)$ \\
$\mathrm{Mo}-\mathrm{O}$ & $2.19(N=3)$ & $2.19(N=2)$ & $2.21(N=3)$ \\
$\mathrm{Mo}-\mathrm{Cl}$ & - & $2.36(N=2)$ & $2.39(N=3)$ \\
$\mathrm{Mo}-\mathrm{P}$ & - & - & $3.07(N=3)$ \\
\hline
\end{tabular}

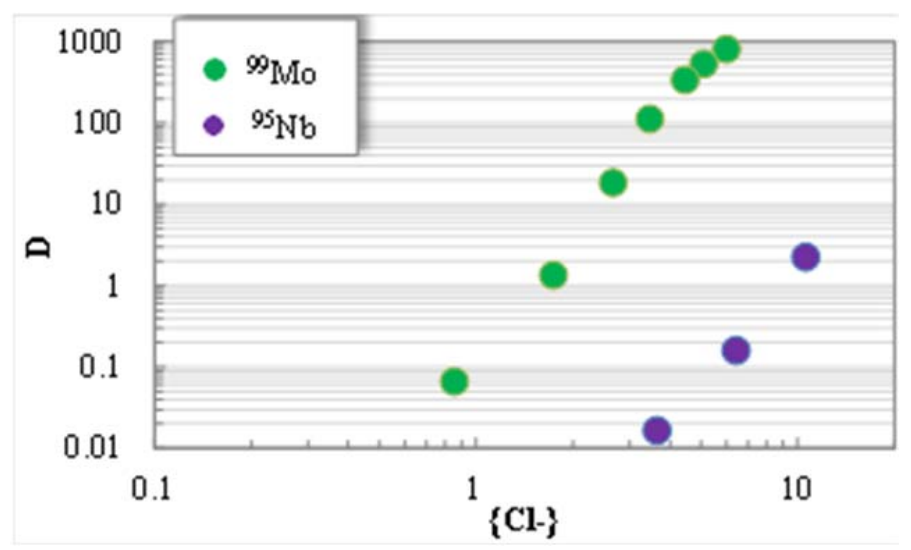

FIGURE 5 Extraction of ${ }^{99} \mathrm{Mo}$ and ${ }^{95} \mathrm{Nb}$ by $30 \%$ TBP/TCE as a Function of HCl

The Mo XAFS data in 30\% TBP in n-dodecane (Figure 4) have a very strong resemblance to those measured for $5 \mathrm{M} \mathrm{HCl}$. This finding suggests that the majority of the Mo is complexed with chloride in the organic phase.

\subsubsection{H/KCl Extraction}

Table 3 lists the results of $\mathrm{HCl}$ and $\mathrm{K}^{+}$extractions into fresh $30 \%$ TBP in TCE. The final acid concentrations did not appreciably deviate from the initial and may be within the standard deviations. Some $\mathrm{HCl}$ may have been extracted from $4.23 \mathrm{M}$, but the most convincing evidence of $\mathrm{HCl}$ extraction was observed for the $6 \mathrm{M}$ system. The same $6 \mathrm{M}$-contacted organic phase sample was titrated in acetone, and the resulting distribution ratio for the acid concentration was calculated to be approximately 0.02. As expected, the data in Table 3 suggest that potassium chloride's partitioning into the solvent is insignificant. 
TABLE 3 The Effect of $30 \%$ TBP/TCE Extraction on the Initial Concentrations (M) of $\mathrm{HCl}$ and $\mathrm{K}^{+}\left(\mathrm{T}=25^{\circ} \mathrm{C}\right)$

\begin{tabular}{ccccc}
\hline$[\mathrm{HCl}]_{0}$ & {$[\mathrm{HCl}]_{f}$} & $\mathrm{D}(\mathrm{HCl})$ & {$\left[\mathrm{K}^{+}\right]_{0}$} & {$\left[\mathrm{~K}^{+}\right]_{f}$} \\
\hline & & & & \\
2.11 & 2.12 & - & $0.072 \pm 0.007$ & $0.072 \pm 0.007$ \\
2.91 & 2.93 & - & $0.070 \pm 0.007$ & $0.074 \pm 0.007$ \\
3.84 & 3.91 & - & $0.074 \pm 0.007$ & $0.073 \pm 0.007$ \\
4.23 & 4.17 & 0.01 & $0.066 \pm 0.006$ & $0.068 \pm 0.006$ \\
6.0 & 5.86 & 0.02 & - & - \\
\hline
\end{tabular}

\subsubsection{Extraction Behavior of $\mathrm{Zr}$ and $\mathrm{Nb}$}

The extraction of trace ${ }^{95} \mathrm{Zr} /{ }^{95} \mathrm{Nb}$ by $30 \% \mathrm{TBP}$ (TCE) from $\mathrm{HCl}$ was determined by gamma spectroscopy $\left({ }^{95} \mathrm{Zr}=724 \mathrm{keV} ;{ }^{95} \mathrm{Nb}=766 \mathrm{keV}\right)$. Only $\mathrm{Nb}$ was extracted; $\mathrm{Zr}$ remained in the aqueous phase in the range of $1-5 \mathrm{M} \mathrm{HCl}$. At $1 \mathrm{M} \mathrm{HCl}$, the distribution of $\mathrm{Nb}$ was too low to measure, but the extraction increased by nearly a $5^{\text {th }}$-order dependence with 3,4 , and $5 \mathrm{M} \mathrm{HCl}$. The test at $5 \mathrm{M} \mathrm{HCl}$ was conducted in the presence of $0.3 \mathrm{M}$ Mo with the same distribution ratio of $\mathrm{D}_{N b}=2.8$. The data are presented in Figure 7 as a function of chloride activity. These results suggest that in the presence of trace impurities, $5 \mathrm{M} \mathrm{HCl}$ forward extraction and scrub may contaminate the organic phase with $\mathrm{Nb}$. At $4 \mathrm{M} \mathrm{HCl}$, however, $\mathrm{D}_{N b}$ is approximately 0.16 , which should be low enough to scrub niobium from the solvent and out of the Mo product.

\subsection{BATCH STUDIES WITH 1-OCTANOL AS DILUENT}

\subsubsection{Extraction of $\mathrm{HCl}$ by $50 \%$ TBP in 1-Octanol}

Extraction of hydrochloric acid by 50\% TBP in 1-octanol was determined by potentiometric titration. An aliquot of organic phase containing $\mathrm{HCl}$ after two extraction steps was titrated in acetone/water mixture using a standard solution of $0.1 \mathrm{M} \mathrm{NaOH}$. Experimental results are shown in Figure 8. 


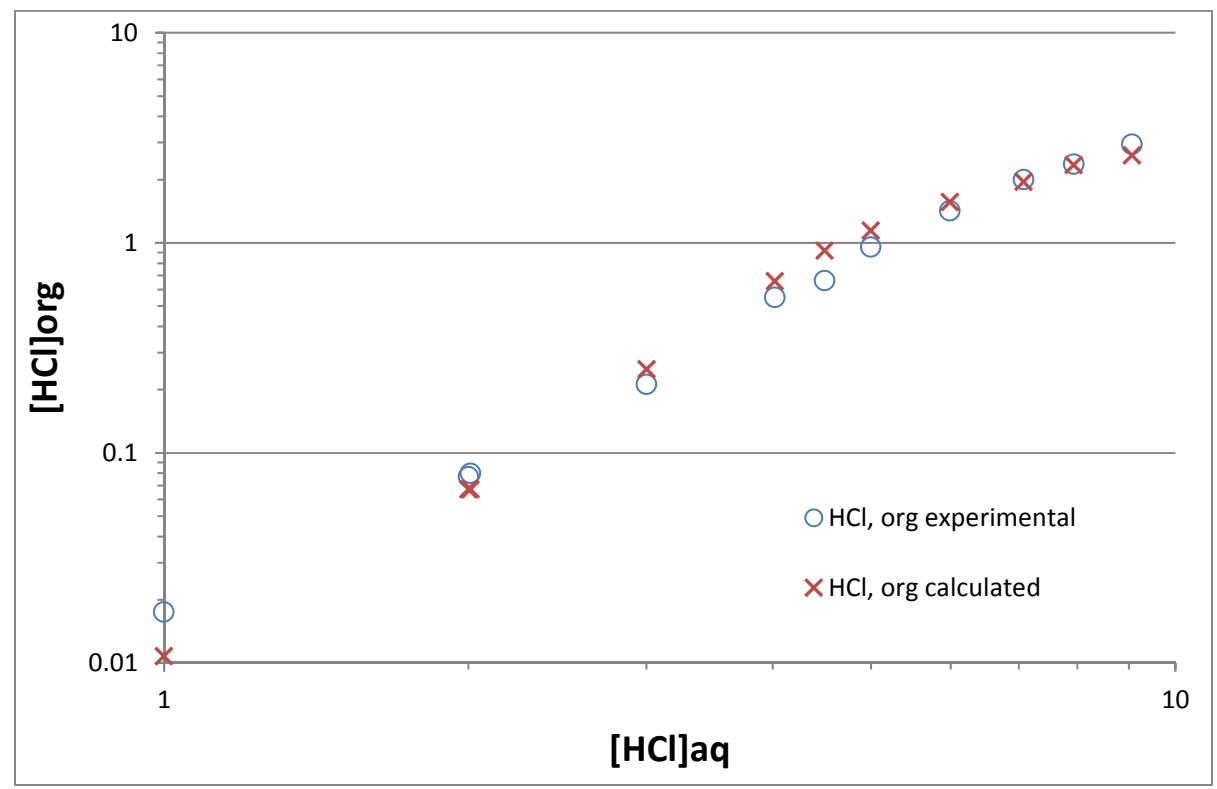

FIGURE 8 Extraction of HCl by 50\% TBP in 1-Octanol

Extraction constants were determined by using Solver in Excel and considering several adducts. Very good correlation between experimental and calculated results was obtained (Figure 8) after including these species:

$$
\begin{gathered}
\mathrm{TBP}+\mathrm{HCl} \leftrightarrow \mathrm{TBP} \cdot \mathrm{HCl} \quad\left(\mathrm{K}_{\mathrm{a} 1}\right) \\
\mathrm{TBP}+2 \mathrm{HCl} \leftrightarrow \mathrm{TBP} \cdot 2 \mathrm{HCl} \quad\left(\mathrm{K}_{\mathrm{a} 2}\right)
\end{gathered}
$$

Total concentration of TBP in the absence of Mo can be written as follow:

$$
T B P_{T}=T B P_{f}+\mathrm{TBP} \cdot \mathrm{HCl}+\mathrm{TBP} \cdot 2 \mathrm{HCl}
$$

Microsoft Solver was used to find $\mathrm{K}_{\mathrm{a} 1}$ and $\mathrm{K}_{\mathrm{a} 2}$ with the following equation:

$$
T B P_{f}=\frac{T B P_{T}}{1+K_{a 1}\{H\}\{C l\}+K_{a 2}\{H\}^{2}\{C l\}^{2}}
$$

The extraction constants determined using Solver were $\mathrm{K}_{\mathrm{al}}=8.0 \times 10^{-3}$ for the TBP.HCl adduct and $\mathrm{K}_{\mathrm{a} 2}=1.94 \times 10^{-6}$ for the TBP. $2 \mathrm{HCl}$ adduct. The extraction of $\mathrm{HCl}$ by the $50 \% \mathrm{TBP} / 1$-octanol system is significantly higher compared to that of the TBP/TCE system described in Section 2.1.4. 


\subsubsection{Extraction of Mo by $50 \%$ TBP in 1-Octanol}

Extraction studies of trace Mo were performed from a wide range of $\mathrm{HCl}$ concentrations. Experimental D values are summarized in Figure 9. Very good extraction of Mo is observed in a wide range of $\mathrm{HCl}$ concentrations, with the highest $\mathrm{D}$ values at $5 \mathrm{M} \mathrm{HCl}$. Distribution ratios for potassium determined using ICP-MS were very low, usually below 0.01 , which leads to very good separation factors of $>1000$.

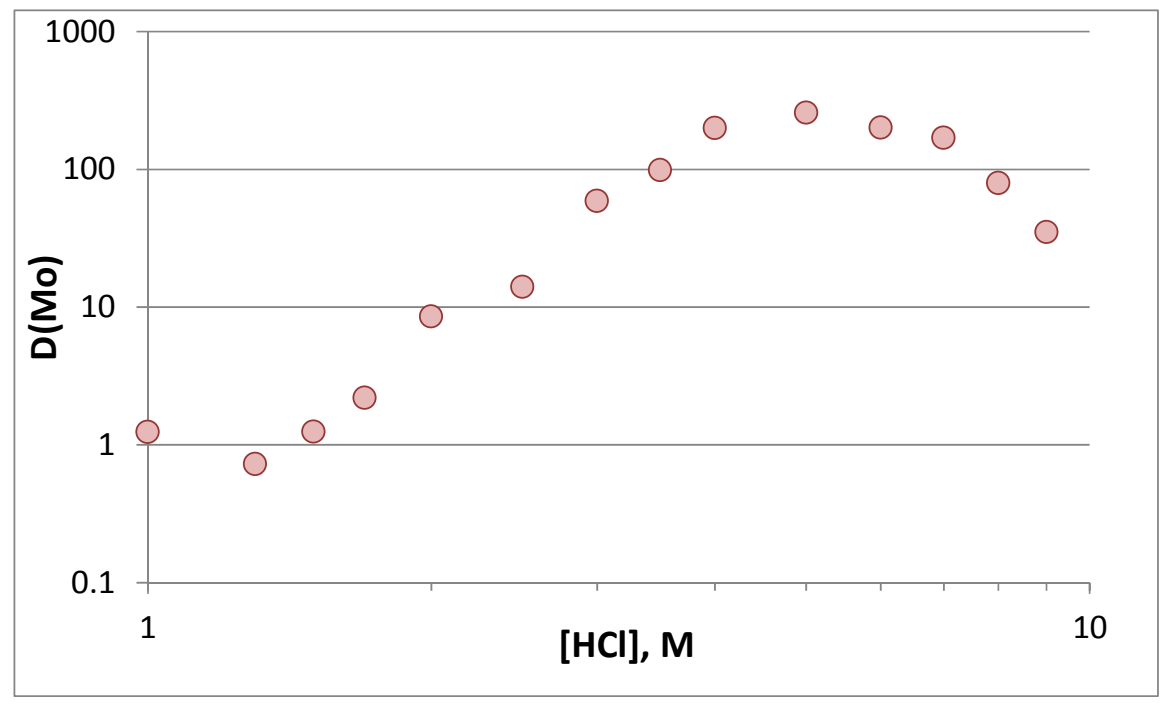

FIGURE 9 Distribution Ratios of Trace Mo for $50 \%$ TBP in 1-Octanol from $\mathrm{HCl}$

Very interesting behavior is observed for low $\mathrm{HCl}$ concentrations. The $\mathrm{D}$ value of Mo for $1 \mathrm{M} \mathrm{HCl}$ is 1.24 while that for $1.3 \mathrm{M} \mathrm{HCl}$ is 0.73 . With further increase in $\mathrm{HCl}$ concentration up to $5 \mathrm{M} \mathrm{HCl}$, the $\mathrm{D}$ values increase. This behavior could indicate extraction of different $\mathrm{Mo}$ species at lower $\mathrm{HCl}$ concentration.

Distribution ratios performed with $0.1 \mathrm{M}$ Mo from 1,3, 7, and $9 \mathrm{M} \mathrm{HCl}$ confirm that different Mo species may form at low $\mathrm{HCl}$ concentration. Figure 10 shows formation of a blue color in the organic phase after extraction of $0.1 \mathrm{M} \mathrm{Mo}$ from $1 \mathrm{M} \mathrm{HCl}$. This color became darker after several days. Distribution ratios for $0.1 \mathrm{M}$ Mo are listed in Table 4. 


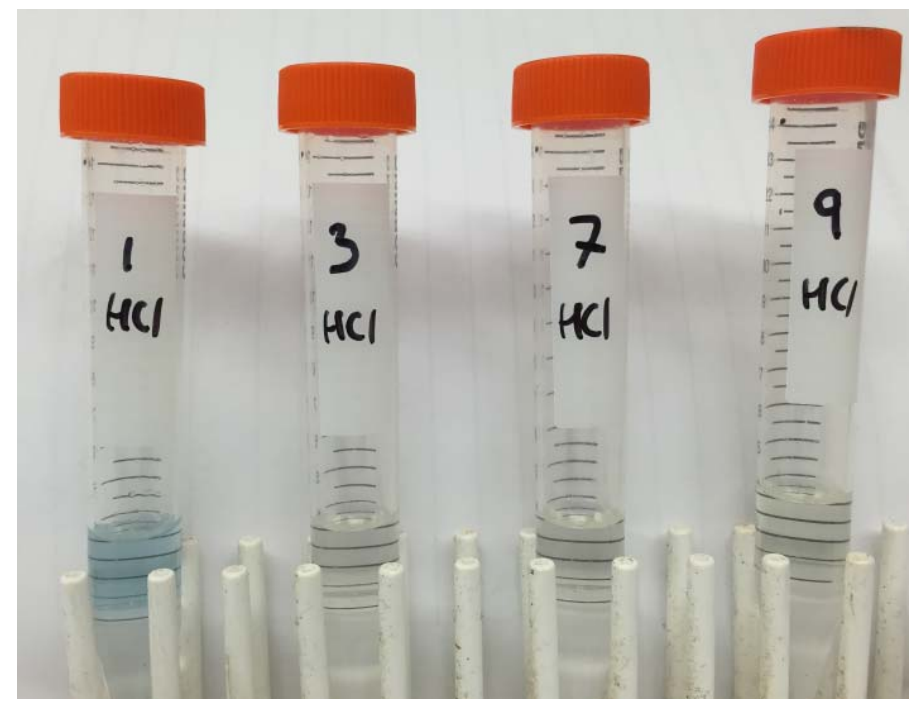

FIGURE 10 Photograph of Organic (top) and Aqueous (bottom) Phases after Extraction from 0.1 M Mo in 1, 3, 7, and 9 M HCl. Molybdenum-blue species formed in the organic phase over time after extraction from $1 \mathrm{M} \mathrm{HCl}$.

TABLE 4 Distribution ratios of $0.1 \mathrm{M}$ Mo from 1, 3, 7, and $9 \mathrm{M} \mathrm{HCl}$

\begin{tabular}{cccc}
\hline & & & \\
Mo, M & HCl, M & D & Mo Extracted, \% \\
\hline & & & \\
0.0961 & 1 & 0.84 & $46 \%$ \\
0.0963 & 3.03 & 10.7 & $91 \%$ \\
0.0961 & 7.08 & 94 & $99 \%$ \\
0.0958 & 9.07 & 56 & $98 \%$ \\
\hline
\end{tabular}

It was also determined that relatively high Mo concentration can be used to effectively extract Mo by 50\% TBP in octanol. A surrogate spent-generator solution that was $0.2 \mathrm{~g}-\mathrm{Mo} / \mathrm{mL}$ as $\mathrm{K}_{2} \mathrm{MoO}_{4}$ in $5 \mathrm{M} \mathrm{KOH}$ was diluted with $\mathrm{HCl}$ to yield different $\mathrm{Mo}$ and $\mathrm{HCl}$ concentrations; $10.5 \mathrm{M} \mathrm{HCl}$ was used to dilute the highly alkaline Mo solution. Data are summarized in Table 5. The conversion of potassium molybdate from highly alkaline solution into molybdenyl dichloride after addition of $\mathrm{HCl}$ can be expressed as follow:

$$
\mathrm{K}_{2} \mathrm{MoO}_{4}+4 \mathrm{HCl} \leftrightarrow \mathrm{MoO}_{2} \mathrm{Cl}_{2}+2 \mathrm{KCl}+2 \mathrm{H}_{2} \mathrm{O}
$$

Therefore, the $\mathrm{HCl}$ concentration after dilution, c'( $\mathrm{HCl})$, can be expressed as follow:

$$
c^{\prime}(\mathrm{HCl})=\frac{\mathrm{c}(\mathrm{HCl}) * \mathrm{~V}(\mathrm{HCl})-4 \mathrm{~V}(\mathrm{Mo}) * \mathrm{c}(\mathrm{Mo})-\mathrm{V}(\mathrm{KOH}) * \mathrm{c}(\mathrm{KOH})}{V^{\prime} \text { sol }}
$$


TABLE 5 Extraction of High Mo Concentration after Dilution of Spent Generator Surrogate Solution with HCl

\begin{tabular}{cccccc}
\hline $\begin{array}{c}0.2 \mathrm{~g}-\mathrm{Mo} / \mathrm{mL} \text { in } \\
5 \mathrm{M} \mathrm{KOH}, \mathrm{mL}\end{array}$ & $\begin{array}{c}10.5 \mathrm{M} \mathrm{HCl}, \\
\mathrm{mL}\end{array}$ & $\mathrm{HCl}, \mathrm{M}$ & $\mathrm{Mo}, \mathrm{M}$ & $\mathrm{D}(\mathrm{Mo})$ & $\begin{array}{c}\% \mathrm{Mo} \\
\text { Extracted }\end{array}$ \\
\hline & & & & & \\
1 & 4.75 & 6.4 & 0.351 & 40.52 & $97.6 \%$ \\
1 & 4.50 & 6.2 & 0.367 & 38.68 & $97.5 \%$ \\
1 & 4.25 & 6.0 & 0.385 & 33.51 & $97.1 \%$ \\
1 & 4.00 & 5.8 & 0.404 & 37.96 & $97.4 \%$ \\
1 & 3.50 & 5.3 & 0.449 & 34.78 & $97.2 \%$ \\
\hline
\end{tabular}

Very high extraction yields were observed even for $\sim 0.45 \mathrm{M}$ Mo. A significant amount of precipitate formed shortly after dilution due to the limited solubility of $\mathrm{KCl}$ under the given conditions. The potassium concentration for several dilutions was measured by ICP-MS. Data are reported in Table 6 and show that, for very low dilutions, Mo can start precipitating together with $\mathrm{KCl}$. The dependence of potassium concentration on the final $\mathrm{HCl}$ concentration is shown in Figure 11.

Due to the limited solubility of $\mathrm{KCl}$, a significant amount of $\mathrm{K}$ is removed just by acidifying with $\mathrm{HCl}$. At higher $\mathrm{HCl}$ concentrations $(6 \mathrm{M})$, the solubilities of $\mathrm{K}$ and Mo are very similar, but at lower $\mathrm{HCl}$ concentrations, the solubility of $\mathrm{K}$ is significantly higher compared to Mo.

TABLE 6 Concentration of Mo and K Determined by ICP-MS after Dilution of Spent Mo Generator Surrogate Solution with $10.5 \mathrm{M} \mathrm{HCl}$. The ICP-MS results are reported with $10 \%$ uncertainty.

\begin{tabular}{|c|c|c|c|c|c|c|}
\hline \multirow{2}{*}{$\begin{array}{l}2.02 \mathrm{M} \mathrm{Mo} \mathrm{in} \\
5 \mathrm{M} \mathrm{KOH}, \mathrm{mL} \\
\end{array}$} & \multirow{2}{*}{$\begin{array}{c}10.5 \mathrm{M} \mathrm{HCl}, \\
\mathrm{mL}\end{array}$} & \multicolumn{3}{|c|}{$\begin{array}{l}\text { Theor. Concentration after } \\
\text { Dilution }^{\mathrm{a}}\end{array}$} & \multicolumn{2}{|c|}{ Measured } \\
\hline & & $\mathrm{HCl}, \mathrm{M}$ & Mo, M & $\mathrm{K}, \mathrm{M}$ & Mo, M & $\mathrm{K}, \mathrm{M}$ \\
\hline 2 & 9.50 & 6.40 & 0.351 & 1.572 & 0.352 & 0.368 \\
\hline 2 & 9.00 & 6.21 & 0.367 & 1.644 & 0.377 & 0.409 \\
\hline 2 & 8.50 & 6.01 & 0.385 & 1.722 & 0.398 & 0.435 \\
\hline 2 & 8.00 & 5.78 & 0.404 & 1.808 & 0.411 & 0.468 \\
\hline 2 & 7.50 & 5.53 & 0.425 & 1.903 & 0.437 & 0.514 \\
\hline 2 & 7.00 & 5.26 & 0.449 & 2.009 & 0.467 & 0.624 \\
\hline 2 & 6.50 & 4.95 & 0.475 & 2.127 & 0.490 & 0.647 \\
\hline 2 & 6.00 & 4.60 & 0.505 & 2.260 & 0.510 & 0.724 \\
\hline 2 & 5.50 & 4.21 & 0.539 & 2.411 & 0.527 & 0.790 \\
\hline 2 & 5.00 & 3.76 & 0.577 & 2.583 & 0.545 & 0.841 \\
\hline
\end{tabular}

a Assuming no precipitation of the chloride salt. 


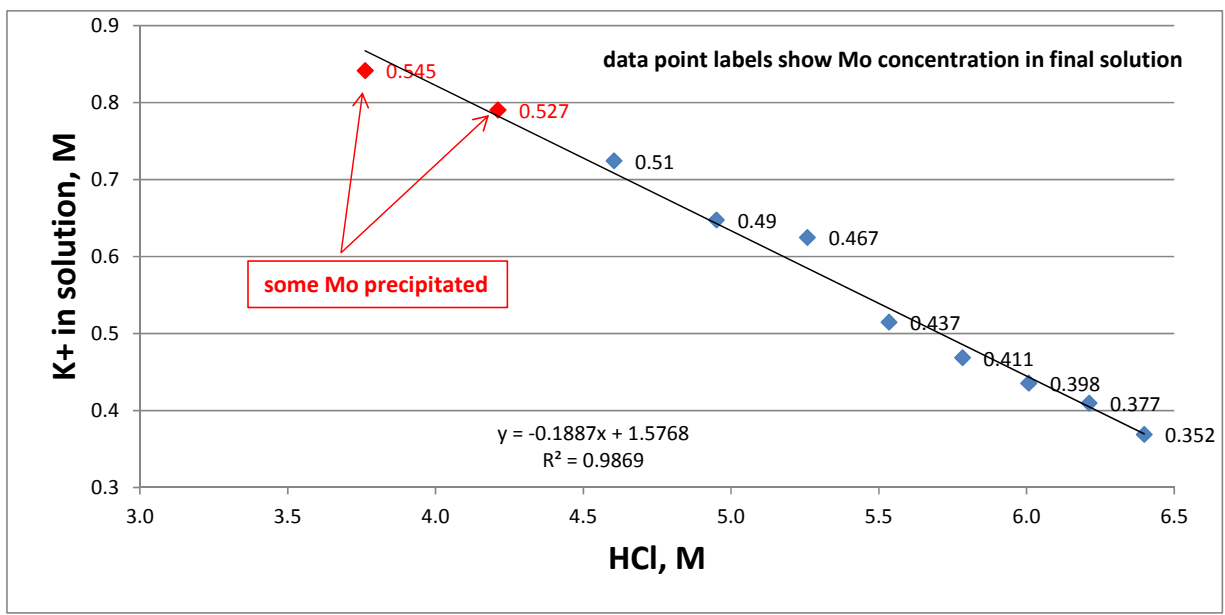

\section{FIGURE 11 Saturated Concentration of $K$ after Dilution of Spent} Generator Surrogate Solution with HCl

\subsubsection{Stripping of Mo from TBP}

It was determined that concentrated $\mathrm{NH}_{4} \mathrm{OH}$ is very effective in stripping Mo from TBP. Nearly quantitative removal of Mo from the organic phase can be achieved in a single contact with an organic/aqueous volume ratio of $1: 1$ if concentrated $\mathrm{NH}_{4} \mathrm{OH}$ is used. However, when $\mathrm{NH}_{4} \mathrm{OH}$ is contacted with the TBP solvent loaded with Mo, a precipitate forms for a short period of time, but it re-dissolves after vigorous mixing (vortex). This effect is due to the changes in speciation of molybdenum from from molybdenyl $\mathrm{MoO}_{2}{ }^{2+}$ to ammonium heptamolybdate $\left(\mathrm{NH}_{4}\right)_{6} \mathrm{Mo}_{7} \mathrm{O}_{24}$, and formation of ammonium chloride, which reach solubility limits in TBP phase but re-dissolve quickly in aqueous phase.

Based on the very good stripping behavior of Mo with concentrated $\mathrm{NH}_{4} \mathrm{OH}$, a batch experiment was performed with extraction of Mo by 50\% TBP in 1-octanol from $5 \mathrm{M} \mathrm{HCl}$. After extraction, the TBP phase containing Mo was scrubbed twice with $5 \mathrm{M} \mathrm{HCl}$, and then Mo was stripped using $20-22 \% \mathrm{NH}_{4} \mathrm{OH}$. Data are given in Table 7 . Approximately $30 \%$ of the potassium was removed by acidifying the starting Mo solution in $5 \mathrm{M} \mathrm{KOH}$ by $\mathrm{HCl}$ addition. The distribution ratio of $\mathrm{K}$ was 0.003 , while that of Mo was 66.6 , giving a $\mathrm{Mo} / \mathrm{K}$ separation factor of 22,200 . Also, $98 \%$ of total Mo was recovered with $\mathrm{K}$ concentration in the final product of $175 \mathrm{ppm}$. The Mo product from the solvent extraction process is a mixture of ammonium molybdate and ammonium chloride in ammonium hydroxide.

Different ratios of $\mathrm{NH}_{4} \mathrm{OH}$ to TBP were also investigated for stripping Mo from $50 \%$ TBP in 1-octanol. It was determined that $\sim 0.3 \mathrm{M}$ Mo in TBP can be effectively stripped at $\mathrm{TBP} / \mathrm{NH}_{4} \mathrm{OH}$ ratio of $1 / 0.4$. At $1 / 0.2$ ratio, Mo partially precipitates due to neutralization of alkaline strip solution by $\mathrm{H}^{+}$from TBP phase and the attainment of the Mo solubility limit. 
TABLE 7 Relative Concentrations of $M o$ and $K$ in Various Stages of the Extraction of 0.3 M Mo from $5 \mathrm{M}$ HCl using $50 \%$ TBP in 1-Octanol. (ICP-MS data are reported with $10 \%$ uncertainty.)

\begin{tabular}{lcc}
\hline \multicolumn{1}{c}{ Aqueous Fractions } & Mo, \% & K, \% \\
\hline & & \\
Starting Mo in 5 M KOH & $\mathrm{N} / \mathrm{A}$ & $\mathrm{N} / \mathrm{A}$ \\
Mo in 5 M HCl before extraction & $105.2 \%$ & $71.1 \%$ \\
Mo in aq. phase after extraction & $1.6 \%$ & $70.7 \%$ \\
$1^{\text {st }}$ scrub with 5 M HCl & $0.2 \%$ & $0.3 \%$ \\
$2^{\text {nd }}$ scrub with 5 M HCl & $0.2 \%$ & $0.003 \%$ \\
Mo product & $98.0 \%$ & $0.0089 \%$ \\
$\mathrm{NH}_{4} \mathrm{OH}$ waste & $0.0 \%$ & $0.0 \%$ \\
\hline
\end{tabular}

We also looked at various concentrations of $\mathrm{HCl}$ and $\mathrm{NH}_{4} \mathrm{Cl}$ for scrubbing and stripping purposes. To that end, $50 \% \mathrm{TBP}$ in octanol pre-equilibrated with $5 \mathrm{M} \mathrm{HCl}$ was contacted with $\sim 0.3 \mathrm{M} \mathrm{Mo} \mathrm{in} \sim 5 \mathrm{M} \mathrm{HCl}$. The organic phase was then contacted with 3-5 $\mathrm{M} \mathrm{HCl}$ and 3-5 $\mathrm{M} \mathrm{NH}_{4} \mathrm{Cl}$. Distribution ratios of Mo and $\mathrm{K}$ for back-extraction are listed in Table 8, which show that $\mathrm{NH}_{4} \mathrm{Cl}$ could also be used to strip Mo from TBP.

TABLE 8 Back-Extraction D(Mo) Values from $50 \%$ TBP in 1-Octanol after Extraction of $\sim 0.3 \mathrm{M}$ Mo from 3-5 M HCl. (ICP-MS data are reported with 10\% uncertainty.)

\begin{tabular}{cccccc}
\hline & & & & & \\
$\mathrm{HCl}, \mathrm{M}$ & $\mathrm{D}(\mathrm{Mo})$ & $\mathrm{D}(\mathrm{K})$ & $\mathrm{NH}_{4} \mathrm{Cl}, \mathrm{M}$ & $\mathrm{D}(\mathrm{Mo})$ & $\mathrm{D}(\mathrm{K})$ \\
\hline & & & & & \\
5 & 4.9 & 0.024 & 5 & 0.04 & 0.003 \\
4 & 1.7 & 0.011 & 4 & 0.053 & 0.009 \\
3 & 0.37 & 0.014 & 3 & 0.023 & 0.013 \\
\hline
\end{tabular}

\subsubsection{Conclusion}

Batch experiments performed using 50\% TBP in 1-octanol showed that Mo can be extracted from a wide range of $\mathrm{HCl}$ concentrations. Up to $\sim 0.5 \mathrm{M}$ Mo can still be extracted by the TBP/octanol system. Although $\mathrm{NH}_{4} \mathrm{OH}$ showed very good potential for stripping Mo from organic phase, due to very similar densities between the organic and aqueous phase in the stripping stage, its use may be very limited for the TBP/octanol system employing centrifugal contactors. However, the significant difference in densities between the $\mathrm{NH}_{4} \mathrm{OH}$ and TBP/TCE system allows use of $\mathrm{NH}_{4} \mathrm{OH}$ for stripping. To develop an extraction flowsheet for the Mo recycle process using the $\mathrm{TBP} / \mathrm{TCE} / \mathrm{HCl}$ system, we will perform extraction modeling using the Argonne Model for Universal Solvent Extraction (AMUSE) and will report the results 
separately. Based on the results obtained from batch experiments for both TBP solvents, the flowsheet in Figure 12 is proposed for recovery of Mo using solvent extraction. An ongoing modeling effort will define the optimum number of stages for each section and the flow rates.

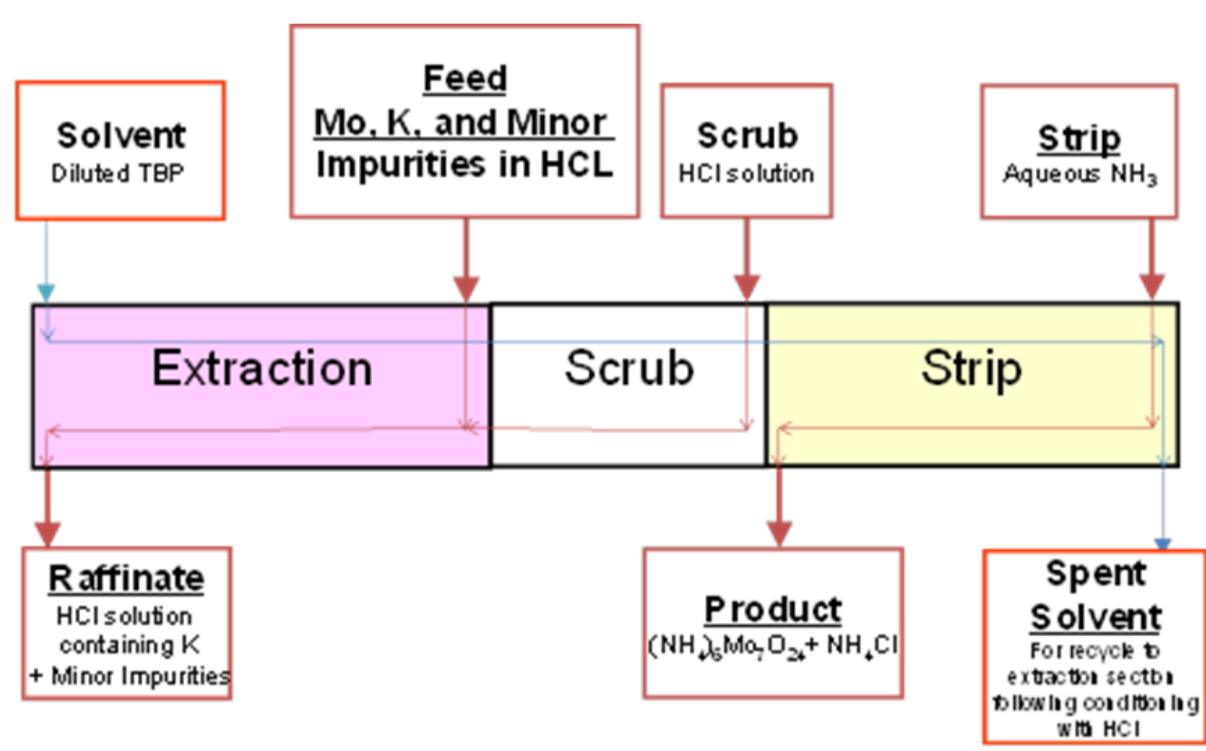

FIGURE 12 Flowsheet of Mo Recovery Process Using Solvent Extraction with TBP

\subsection{MATERIAL COMPATIBILITY AND CONTACTOR HYDRAULIC TESTING}

An Argonne 2-cm annular centrifugal contactor having a 3D printed rotor and housing made of polymethylmethacrylate (PMMA) was fabricated by a stereolithography (SLA) printing for testing with proposed liquid solutions for an enriched molybdenum recycle.

\subsubsection{Density Measurements and Dispersion Testing}

Solutions tested were aqueous phases of $5 \mathrm{M} \mathrm{HCl}(\mathrm{HCl})$ and $22 \% \mathrm{NH}_{4} \mathrm{OH}$ (hydroxide) and organic phases of 50\%TBP in 1-octanol ("octanol") and 30\% TBP in TCE ("TCE") organic phases. Densities of the four solutions were measured in $10 \mathrm{ml}$ volumetric flasks and found to be $1.075,0.929,0.918$, and $1.405 \mathrm{gm} / \mathrm{cm}^{3}$, respectively.

Dispersion tests had been conducted previously (Table 1). Dispersion and separation in a $100 \mathrm{ml}$ graduated cylinder were repeated for hydroxide/octanol and hydroxide/TCE only. Due to the very small density difference between the hydroxide and octanol, it was confirmed that as in earlier tests, the separation was very slow. In contrast, while a dispersion number was not earlier reported for the hydroxide/TCE, separation occurred quite rapidly, and the $\mathrm{N}_{D i}$ was quite high $\left(50 \times 10^{-4}\right)$, indicating good physical separation. 
The very first contact for the two phases resulted in cloudiness of the TCE phase and a greyish film layer between phases that somewhat inhibited separation. Upon subsequent contacts, however, separation was very good. The cloudiness of the TCE phase persisted with no apparent settling of any kind of precipitate for almost $1 \mathrm{hr}$, after which the solution somewhat rapidly became clear. This change is due to the very limited extraction of $\mathrm{HCl}$ by TBP/TCE, which is another advantage of this extraction system.

\subsubsection{Immersion Tests}

Contactor rotors printed in two PMMA materials (opaque-white and clear, both samples from EnvisionTec, Inc.) were immersed in each organic phase (octanol and TCE) to assess material compatibility. Available information suggests that alcohols, in general, are not good for PMMA and that pure TCE is also not recommended. No information was previously available for mixtures of these organics with TBP; however, use of TBP in dodecane has been thoroughly tested with acrylic machined and printed components. Regular measurement was performed of rotor mass and diameter at two heights (rotor bottom and mid-section) across both quadrant pairs (i.e., two measurements at 90 degrees relative to one another) of the rotor.

After $>48 \mathrm{hr}$ of continuous submersion in the octanol phase, no mass or dimensional changes were observed in either the white or clear materials. A qualitative consideration of the materials' strength on manual compression also did not show any change. As noted, tests spanning $\sim 2 \mathrm{hr}$ in an actual operating contactor fabricated from the same materials also did not show any negative effects that would indicate materials incompatibility. Extended duration testing could be performed, but the initial indication is that the octanol organic phase is acceptable for use with PMMA printed components.

As for the TCE phase, immersion tests (using the same two rotors, cleaned and dried) were also conducted. After several hours of exposure, no measurable changes in mass or dimension were observed, and no tactile changes to material strength were identified. However, after longer exposure ( $>24 \mathrm{hr}$ ) and subsequent drying, the clear material (EnvisionTec's 'E-Glass 3SP") showed severe cracking of the thin internal vanes of the rotor, whereas no changes were observed in the opaque-white material after prolonged exposure and drying. Consequently, only the white material (so-called "ABS 3SP White") was used for the rotor and housing in the singlestage test results presented here. Based on previous experience with clear materials from other manufacturers (e.g., 3D Systems Accura 60) for use with other TBP-containing solvents (e.g., 30\% TBP in dodecane), such degradation was not expected. Additional testing in the TBP/TCE solvent using printed PMMA materials from multiple vendors is needed to determine if an adequately resistant clear material can be identified. Testing with pure TCE or pure TBP (such as might be used in a solvent wash step) might also be considered in the future.

\subsubsection{Single-Stage 2-cm Contactor Hydraulic Testing}

A single-stage centrifugal contactor using a printed PMMA housing (white) and rotor (clear) and fluoropolymer fittings (Kynar and Teflon) was constructed for hydraulic testing of 
solutions (see Figure 13). Tests for each phase were performed at various flow rates between 10 and $20 \mathrm{ml} / \mathrm{min}$. Both phases were run in continuous recycle to their respective feed vessels. The hydroxide and octanol phase pair were tested first at an organic/aqueous phase ratio of $\sim 2: 1$ and a total flow rate of $\sim 45 \mathrm{ml} / \mathrm{min}$. Following steady operation with the heavy phase, the light phase (octanol) was introduced, and it was very quickly seen that adequate separation could not be achieved at these or reduced flow rates. Additionally, precipitation of white ammonium chloride solids from aqueous carry-over into the organic feed vessel was observed. The test was halted after only a few minutes. Subsequent calculations using Argonne's design tool for centrifugal contactor rotors (ROTOR) showed that the rotor configuration - namely the relative weir radii - must be modified to achieve separation and, even then, the throughput that could potentially be maintained is only $\sim 5 \mathrm{ml} / \mathrm{min}$, which is more than ten times less than what is typical for these contactors. It should be noted that decreasing the TBP concentration in the octanol could improve the density ratio relative to hydroxide and make the TBP/octanol system also a viable option.

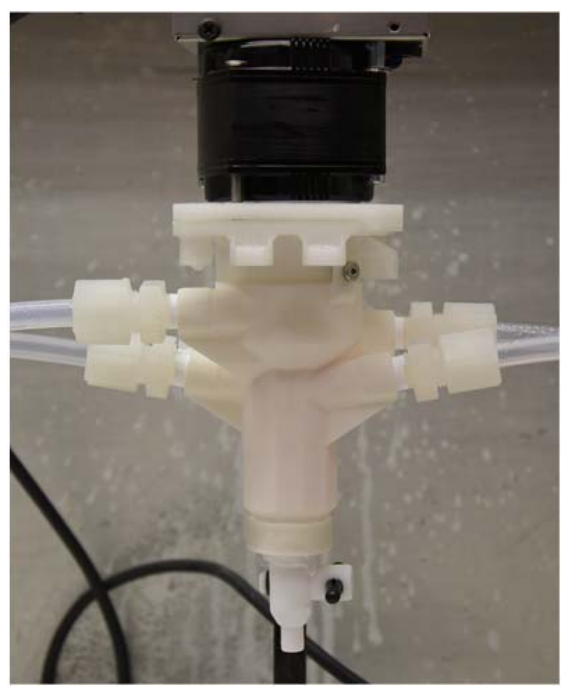

\footnotetext{
FIGURE 13 Snapshot of Printed ANL 2-cm Centrifugal Contactor. Housing is white PMMA, and rotor (not visible) is clear PMMA. Tube fittings are Kynar, and bottom drain is Teflon.
}

Tests using the $\mathrm{HCl} /$ octanol were more successful, though not entirely so. Initially, an organic/aqueous phase ratio of 2:1 was used, but significant organic carry-over to the aqueous effluent occurred. The phase ratio was shifted to slightly less than 1 to achieve aqueous continuous conditions. Organic-phase carryover was found to be lessened but not eliminated.

Subsequent ROTOR calculations showed that the aqueous weir size is just slightly too large to give adequate separation of these two phases. Modification of the weir dimensions is trivial — and not at all costly for printed rotors - but it requires fabrication of a completely new 
rotor. Given this, the $\mathrm{HCl} /$ octanol pair could readily be made to work well in a centrifugal contactor. No mechanical issues for the printed rotor were observed after several hours of testing with the octanol solvent.

Tests with TCE were also performed. With the greater relative density of TCE, it acts as the heavy phase in both extraction and stripping conditions. ROTOR calculations showed that good operation at typical high throughputs could be expected. Due to time constraints, only stripping conditions with hydroxide were tested, though no issues with $\mathrm{HCl}$ were anticipated. Good operation of the contactor was observed at an organic-to-aqueous ratio $(\mathrm{O} / \mathrm{A})$ of approximately 1.5 and a total feed rate of $52.5 \mathrm{ml} / \mathrm{min}$. The contactor was started up with a clean TCE phase (though pre-equilibrated with $\mathrm{HCl}$ ), and upon introduction of the light phase (hydroxide in this case) the effluent TCE phase became cloudy white. At the same time the hydroxide phase also became slightly orange tinted. It is thought that this was due to iron in the system originating from corrosion on the stainless steel fittings and pump on the organic side. While a Teflon pump head, fittings, and lines were used for the $\mathrm{HCl}$ feed in earlier tests, the octanol feed pump had a stainless steel head, fittings, and feed vessel dip tube. While no $\mathrm{HCl}$ had direct contact with these components, it appears that chloride extracted into the octanol phase is sufficient to corrode the stainless steel. A dark green liquid slug appeared upon starting up the pump with TCE. This material was drained from the contactor, but undoubtedly some residual stainless corrosion products remained in the system, accounting for the orangeness of the hydroxide. As with the batch mixing tests, the TCE phase was initially uniformly opaque white but became perfectly clear after about $1 \mathrm{~h}$ of continuous operation. The contactor was operated continuously for more than $2 \mathrm{~h}$, and no significant carry-over of either phase occurred. Mechanical operation of the printed rotor was also unaffected.

Following completion of the hydroxide/TCE contactor test, the rotor was removed, and a brownish layer was seen in the underflow area for the heavy phase (TCE). This is further indication of stainless-steel corrosion products. The rotor was clear of the corrosion products following $\mathrm{HCl}$ /octanol testing, but TCE tests were performed $48 \mathrm{~h}$ later, during which unseen corrosion of the pump components had apparently progressed. However, the brown deposit in the rotor did not appear to affect its operation and should be avoidable if all stainless steel components are removed from the aqueous and organic sides of the system to avoid any issues with $\mathrm{HCl}$ directly or with dissolved chloride in the organic phase.

\subsubsection{Conclusion}

Based on this limited set of tests in an actual laboratory-scale centrifugal contactor, it appears that no issues would be expected with using printed contactors with any of these phases. Additional extended tests may be needed to confirm the long-term robustness of the contactors and identify any slow developing degradation issues, though no measurable changes were observed during these tests.

Barring any materials compatibility issues that arise as immersion testing continues, it also appears that use of TCE as the diluent may have clear benefits to the hydraulic operation of the contactors. This diluent increases the efficiency of physical separation and, consequently, the 
throughput that can be achieved. If no compelling extraction chemistry or materials compatibility issues exist to favor octanol, it would thus appear that TCE is a better solvent choice.

Counter-current testing of the TBP-TCE system was conducted during the preparation of this report. The results of these tests were very positive and will be presented in future publications. Modelling of these systems is near complete and will also be presented in future publications. 


\section{METHODS TO REMOVE $\mathrm{NH}_{4}$ CI FROM THE SOLVENT EXTRACTION PRODUCT}

\subsection{SUBLIMATION}

Molybdenum can be stripped from TBP using $\mathrm{NH}_{4} \mathrm{OH}$ that carries a significant amount of chloride. After evaporating Mo solution from $\mathrm{NH}_{4} \mathrm{OH}$ using a rotary evaporator, we recovered a white solid containing a mixture of ammonium molybdate and ammonium chloride. If this solid is heated, ammonium chloride can be removed by sublimation (decomposition of $\mathrm{NH}_{4} \mathrm{Cl}$ into $\mathrm{NH}_{3}$ and $\mathrm{HCl}$, and recombination into $\mathrm{NH}_{4} \mathrm{Cl}$ upon cooling). Small-scale sublimation was tested in the apparatus shown in Figure 14, where a mixture of $\mathrm{NH}_{4} \mathrm{Cl}$ and $\left(\mathrm{NH}_{4}\right)_{6} \mathrm{Mo}_{7} \mathrm{O}_{24}$ was heated on a hot plate. White fumes indicating decomposition of both ammonium chloride and molybdate started to evolve shortly after the hot plate used for heating was turned on. The ammonium molybdate $\left(\mathrm{NH}_{4}\right)_{6} \mathrm{Mo}_{7} \mathrm{O}_{24} \bullet \mathrm{xH}_{2} \mathrm{O}$ changed upon heating to a gray blue powder. The decomposed Mo product was re-dissolved in $\mathrm{NH}_{4} \mathrm{OH}$, acidified by $\mathrm{HNO}_{3}$, and tested for chlorides by adding $\mathrm{AgNO}_{3}$. No precipitate $(\mathrm{AgCl})$ was formed, indicating that chlorides were effectively removed during the sublimation step. White crystalline $\mathrm{NH}_{4} \mathrm{Cl}$ was collected in a water-cooled condenser placed above the vessel.

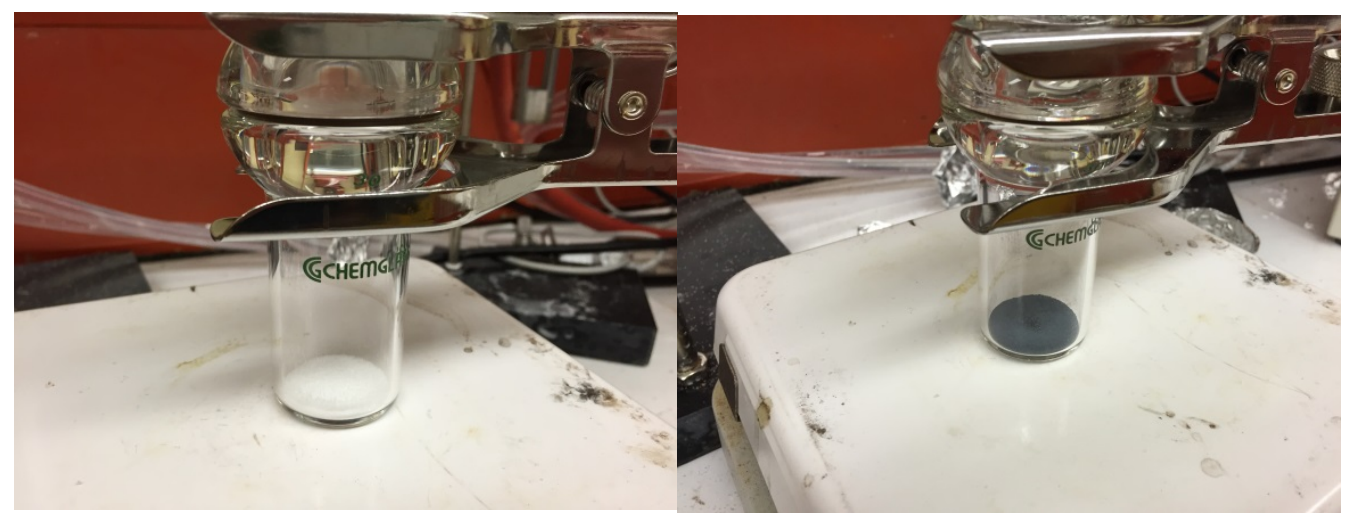

\section{FIGURE 14 Small-scale Apparatus Used for Sublimation of $\mathrm{NH}_{4} \mathrm{Cl}$ from Solid Mixture of $\mathrm{NH}_{4} \mathrm{Cl}$ and $\left(\mathrm{NH}_{4}\right)_{6} \mathrm{Mo}_{7} \mathrm{O}_{24}$}

When $\left(\mathrm{NH}_{4}\right)_{6} \mathrm{Mo}_{7} \mathrm{O}_{24}$ was heated in the absence of $\mathrm{NH}_{4} \mathrm{Cl}$, its color changed from white to dark blue (Figure 14). Upon additional heating at $500^{\circ} \mathrm{C}$, the powder turned yellow. Analysis by XRD confirmed that both the blue and yellow powders were composed mostly of $\mathrm{MoO}_{3}$. When a mixture of $\mathrm{NH}_{4} \mathrm{Cl}$ and $\left(\mathrm{NH}_{4}\right)_{6} \mathrm{Mo}_{7} \mathrm{O}_{24}$ was heated, the powder turned gray-blue and then a yellowish-gray after additional heating at $500^{\circ} \mathrm{C}$. Small portions of $\mathrm{NH}_{3}\left(\mathrm{MoO}_{3}\right)_{3}$ and $\left(\mathrm{NH}_{4}\right)_{4} \mathrm{Mo}_{8} \mathrm{O}_{26}$ were also present in some of the samples.

However, when larger-scale experiments (Figure 15) using $\sim 40-80 \mathrm{~g}$ of a recycled mixture of $\mathrm{NH}_{4} \mathrm{Cl}$ and $\left(\mathrm{NH}_{4}\right)_{6} \mathrm{Mo}_{7} \mathrm{O}_{24}$ were performed, some fraction of Mo was found in the condenser when the mixture was heated at $500^{\circ} \mathrm{C}$. This difference could be due to reaction between $\mathrm{NH}_{4} \mathrm{Cl}$ and $\left(\mathrm{NH}_{4}\right)_{6} \mathrm{Mo}_{7} \mathrm{O}_{24}$ and the formation of $\mathrm{Mo}-\mathrm{Cl}$ species that are volatile. 

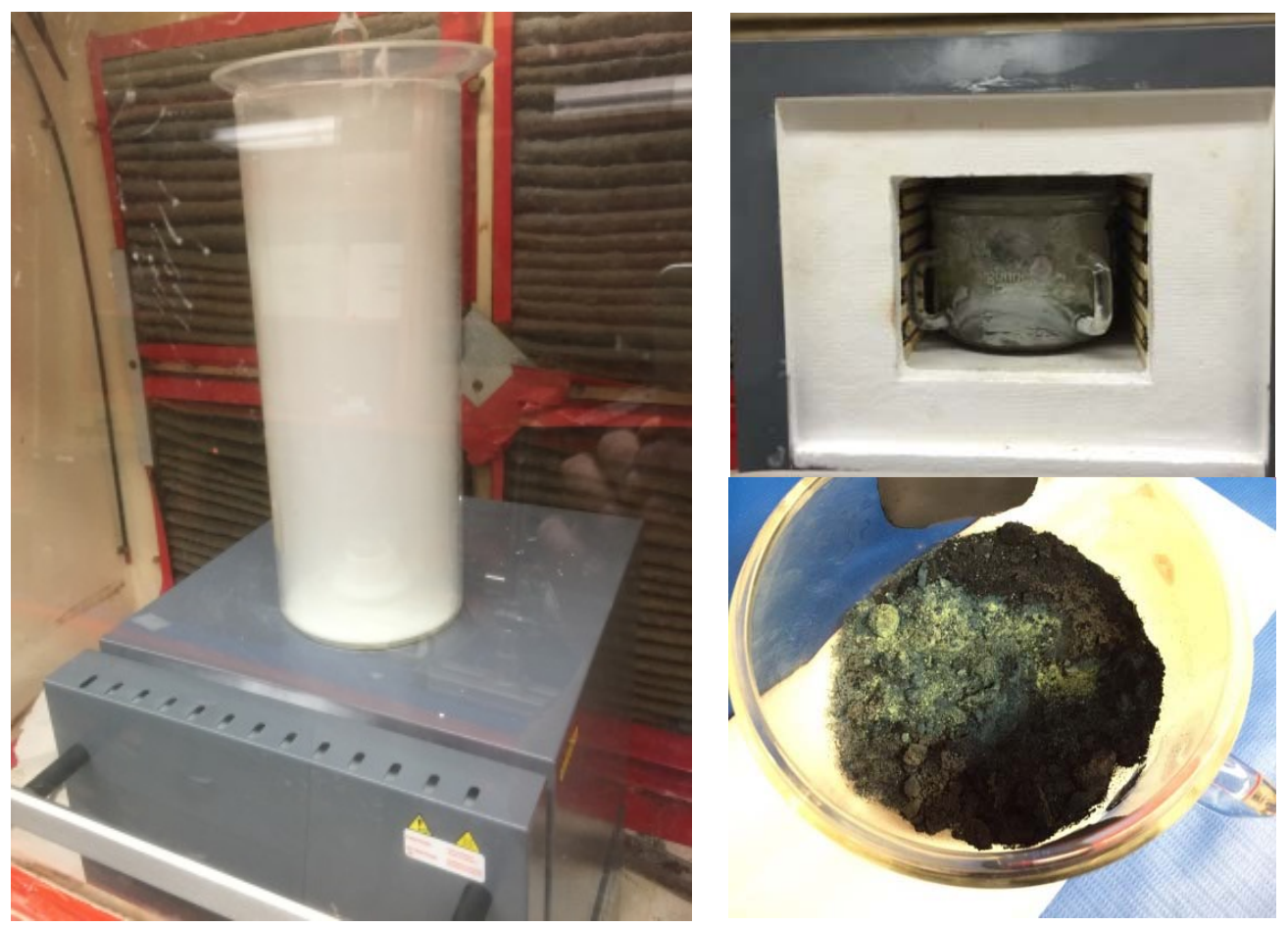

FIGURE 15 Large-Scale Sublimation Apparatus for Separation of $\mathrm{NH}_{4} \mathrm{Cl}$ from $\left(\mathrm{NH}_{4}\right)_{6} \mathrm{Mo}_{7} \mathrm{O}_{24}$ after Solvent Extraction Using TBP. Mixture of yellowish-green solid and bluish-black powder was obtained.

Analysis by XRD also indicated the presence of $\mathrm{MoO}_{2}$. If sublimation is used to remove $\mathrm{NH}_{4} \mathrm{Cl}$ from the product stream, further work is needed to optimize this process.

\subsection{PRECIPITATION OF MOLYBDENUM USING ACETIC ACID}

It was previously demonstrated [1-3] that Mo can be precipitated from alkaline solutions using glacial acetic acid. Since the Mo product from the solvent extraction process is present as a mixture of ammonium molybdate and $\mathrm{NH}_{4} \mathrm{Cl}$ in $\mathrm{NH}_{4} \mathrm{OH}$ solution, it can be removed from the alkaline strip solution by using acetic acid (AcA), and an evaporation step is not necessary. Ammonium chloride stays in the solution, while Mo can be collected by filtration and washed with acetic acid and then with ethanol. The dried white Mo precipitate, obtained after washing with acetic acid and ethanol (Figure 16A), can then be heated at $500^{\circ} \mathrm{C}$ and converted to $\mathrm{MoO}_{3}$ (Figure 16B). However, the white precipitate that forms after precipitation with glacial acetic acid is not very easy to work with since it is very wet and "sticky", which was the case even after washes with ethanol. 


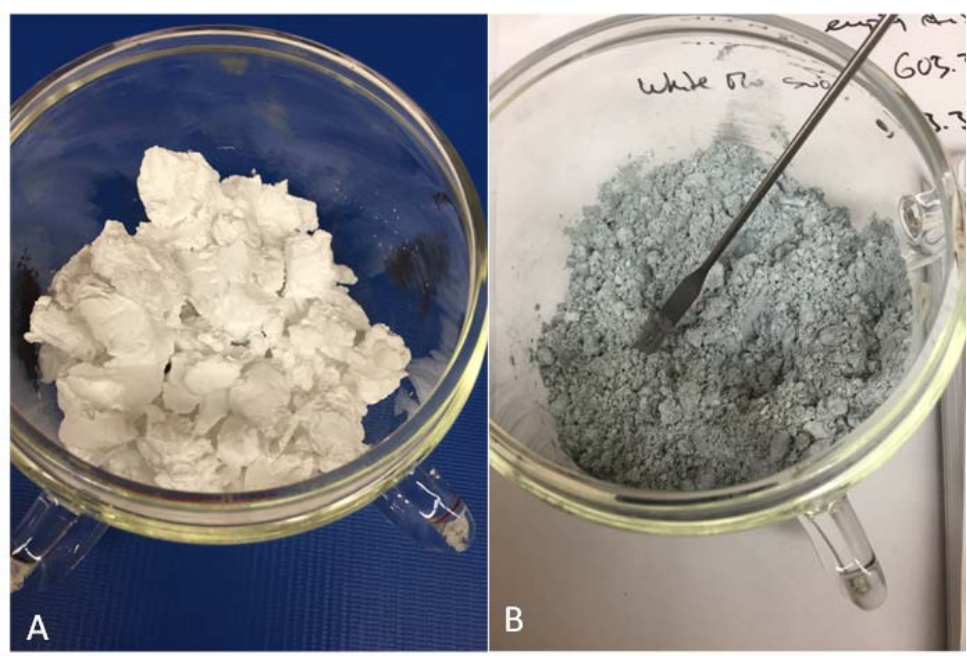

FIGURE 16 Photographs of (A) White Mo Solid

Obtained after Precipitation with AcA and (B) $\mathrm{MoO}_{3}$

Product Obtained after Heating at $500^{\circ} \mathrm{C}$

\subsection{REMOVAL OF $\mathrm{NH}_{4} \mathrm{CI}$ USING DIFFERENTIAL SOLUBILITY}

The above results indicate that an ethanol-water mixture for removal of $\mathrm{NH}_{4} \mathrm{Cl}$ from solid ammonium molybdate- $\mathrm{NH}_{4} \mathrm{Cl}$ mixture is advantageous compared to the AcA or sublimation options. If acetic acid is used to precipitate $\mathrm{Mo}$ from $\mathrm{NH}_{4} \mathrm{OH}$ strip solution, the acetic acid fraction cannot be easily recycled, and an ethanol wash still needs to be used to remove acetic acid from the solid Mo precipitate. If only ethanol-water mixture is used, dissolved $\mathrm{NH}_{4} \mathrm{Cl}$ can be removed from the ethanol solution by rotary evaporation, while ethanol can be re-used. We found that a residue of octanol-TBP mixture can be easily removed by ethanol wash, which would otherwise be left in the final Mo product. By using ethanol, we minimized the waste stream to mostly solid $\mathrm{NH}_{4} \mathrm{Cl}$, since ethanol can be fully recycled. Figure 17A shows recovered ammonium heptamolybdate, and Figure $17 \mathrm{~B}$, the $\mathrm{MoO}_{3}$ product after heating at $500^{\circ} \mathrm{C}$.

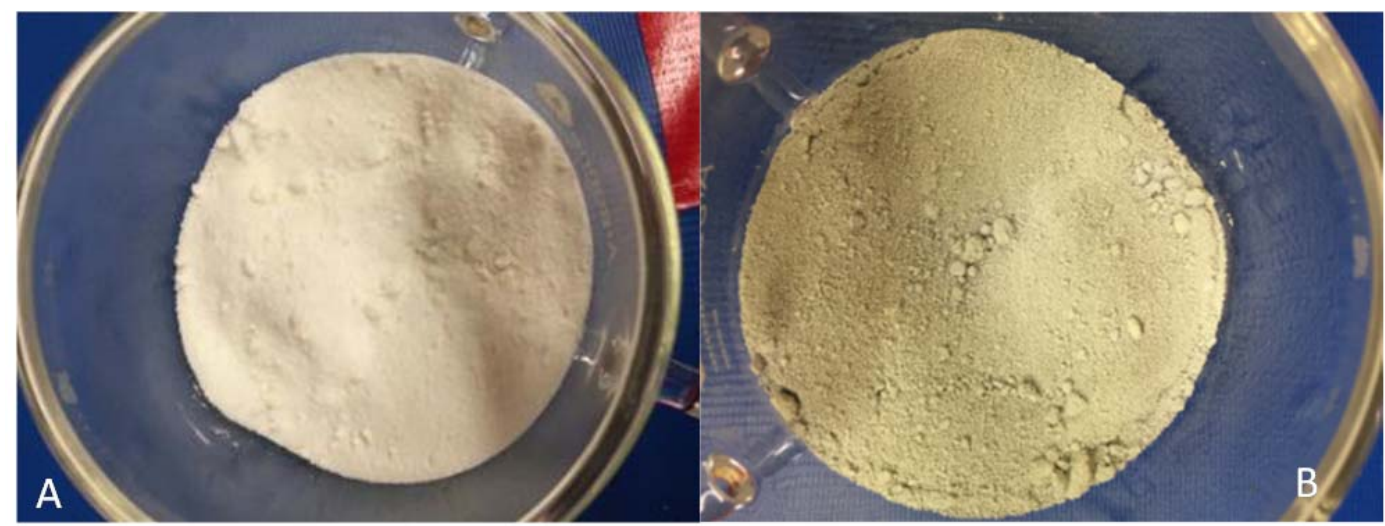

FIGURE 17 Photographs of (A) Ammonium Molybdate Obtained after Wash with Ethanol-Water Mixture and (B) $\mathrm{MoO}_{3}$ Product Obtained after Heating at $500^{\circ} \mathrm{C}$ 
Since the particle size of recovered $\mathrm{MoO}_{3}$ is important for the reduction step when $\mathrm{MoO}_{3}$ is reduced to $\mathrm{MoO}_{2}$ and then to Mo-metal particles, we also looked at particle sizes of both ammonium molybdate and $\mathrm{MoO}_{3}$ (Figure 18). Although the particle size of recycled $\left(\mathrm{NH}_{4}\right)_{6} \mathrm{Mo}_{7} \mathrm{O}_{24}$ is mostly in the range of 200-300 $\mu \mathrm{m}$ (A and $\mathrm{B}$ in Figure 18), the decomposition step of molybdate to $\mathrm{MoO}_{3}$ particles at $500^{\circ} \mathrm{C}$ led to significantly smaller particle size of only few micrometers $(\mathrm{C}$ and $\mathrm{D})$. However, when this $\mathrm{MoO}_{3}$ was further heated at $650^{\circ} \mathrm{C}$, significant growth in particle size occurred, and needle-like particles of $\mathrm{MoO}_{3}$ formed ( $\mathrm{E}$ and $\mathrm{F}$ ).

Work involving optimization of particle size for both ammonium molybdate and molybdenum trioxide is discussed in more detail in Section 5, and we plan to investigate this task in more detail in the future.

\subsection{CONCLUSION}

Three methods were developed for removal of ammonium chloride from the molybdenum product of the solvent extraction process. The low sublimation point of $\mathrm{NH}_{4} \mathrm{Cl}$ can be used to selectively remove $\mathrm{NH}_{4} \mathrm{Cl}$, while ammonium molybdate decomposes to form $\mathrm{MoO}_{3}$. However, $\mathrm{NH}_{4} \mathrm{Cl}$ and $\left(\mathrm{NH}_{4}\right)_{6} \mathrm{Mo}_{7} \mathrm{O}_{24}$ can react together, which limits the separation. The process would need to be further optimized to minimize Mo losses during this step. Also, glacial acetic acid can be used to selectively precipitate Mo from alkaline strip solution. The Mo precipitate can be then washed with acetic acid and ethanol and converted to $\mathrm{MoO}_{3}$ upon heating. Use of $80 \%$ ethanol seems to be the best option, since while removing $\mathrm{NH}_{4} \mathrm{Cl}$, it can also remove any organics that are carried over or dissolve in the ammonium hydroxide. 


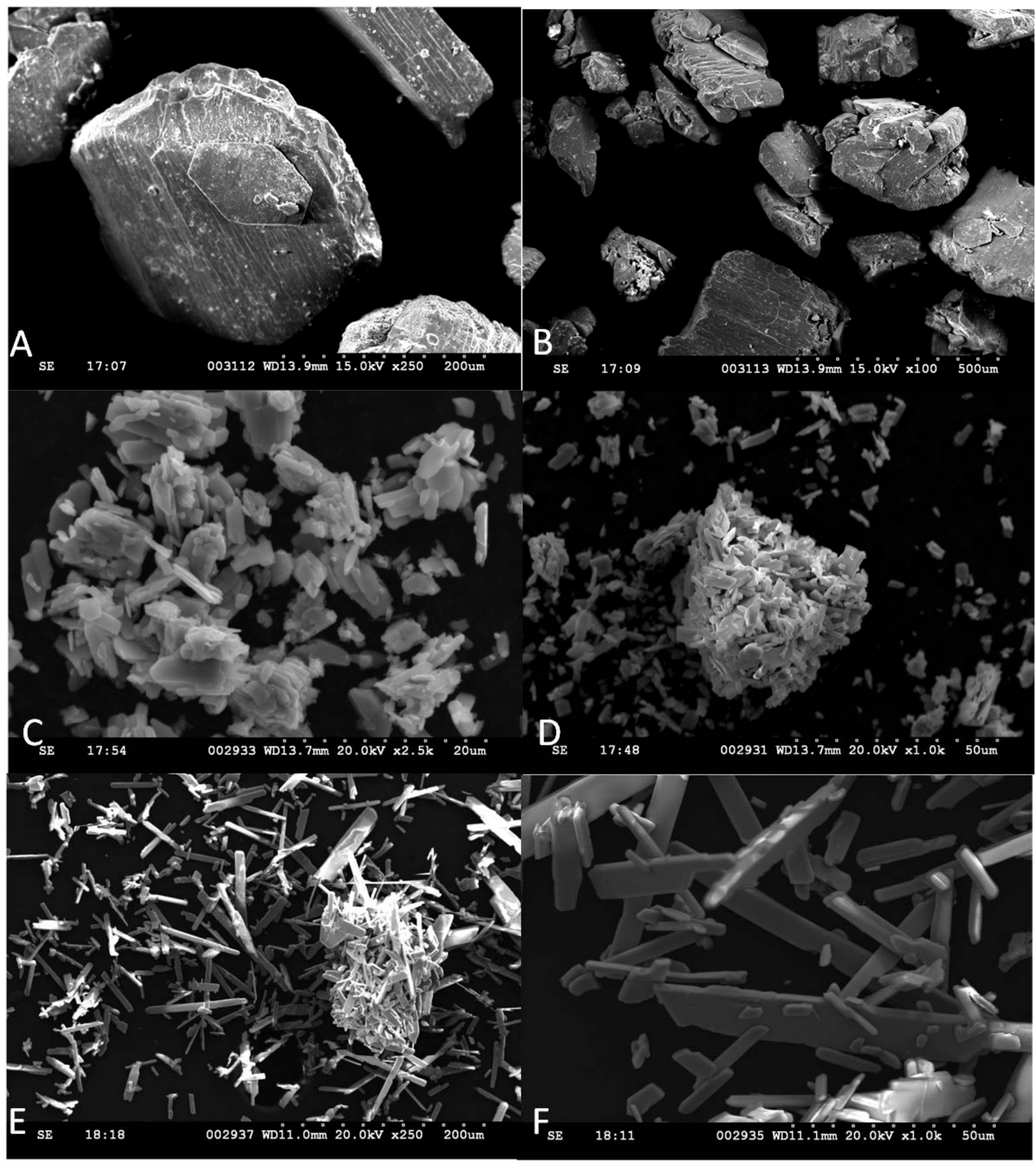

FIGURE 18 SEM Images of (A, B) Ammonium Molybdate Recycled from Solvent Extraction Process, (C, D) Molybdenum Trioxide Obtained after Decomposition of Molybdate at $500^{\circ} \mathrm{C}$, and (E, F) Molybdenum Trioxide Obtained after Heating at $650^{\circ} \mathrm{C}$ 


\section{LARGE-SCALE RECYCLE PROCESS USING SOLVENT EXTRACTION}

Several large-scale experiments using a surrogate spent-generator solution with $0.2 \mathrm{~g}-\mathrm{Mo} / \mathrm{ml}$ in $\sim 5 \mathrm{M} \mathrm{KOH}$ solution were performed. About $700 \mathrm{~mL}$ of $\mathrm{K}_{2} \mathrm{MoO}_{4}$ in $\sim 5 \mathrm{M} \mathrm{KOH}$, which was obtained after dissolving sintered Mo disks, was diluted with $1260 \mathrm{~mL}$ of water and acidified with $2450 \mathrm{~mL}$ of $\sim 11.5 \mathrm{M} \mathrm{HCl}$ to make $4.4 \mathrm{~L}$ of a yellow solution (4.3 M HCl). The acidified Mo solution was contacted with $\sim 4.4 \mathrm{~L}$ of $50 \%$ TBP in 1-octanol to extract the Mo. The phases were separated with a $5 \mathrm{~L}$ funnel (Figure 19), and aqueous phase was contacted with $1.5 \mathrm{~L}$ of a fresh portion of $50 \%$ TBP. The combined organic phase $(\sim 6 \mathrm{~L})$ was yellow due to the presence of Mo, while the aqueous phase was almost colorless after extraction. Impurities in the organic phase were scrubbed in two steps using $\sim 1.5 \mathrm{~L}$ and $\sim 0.9 \mathrm{~L}$ of $\sim 5 \mathrm{M} \mathrm{HCl}$. The Mo was then stripped using $\sim 6 \mathrm{~L}$ of $\mathrm{NH}_{4} \mathrm{OH}\left(\sim 23 \% \mathrm{NH}_{3}\right)$. The $\mathrm{NH}_{4} \mathrm{OH}$ was evaporated using a rotary evaporator, and a mixture of ammonium molybdate and ammonium chloride salts was recovered (Figure 20).

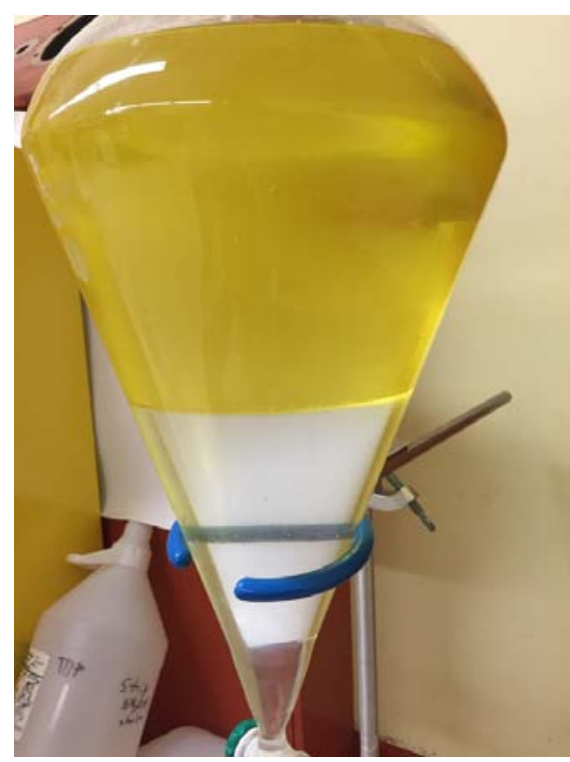

FIGURE 19 Funnel Used for Separation of Mo from Solution. Organic phase (on top) turned yellow after Mo was extracted from $\mathrm{HCl}$ solution, while aqueous phase (that was yellow when containing Mo) turned to almost colorless.

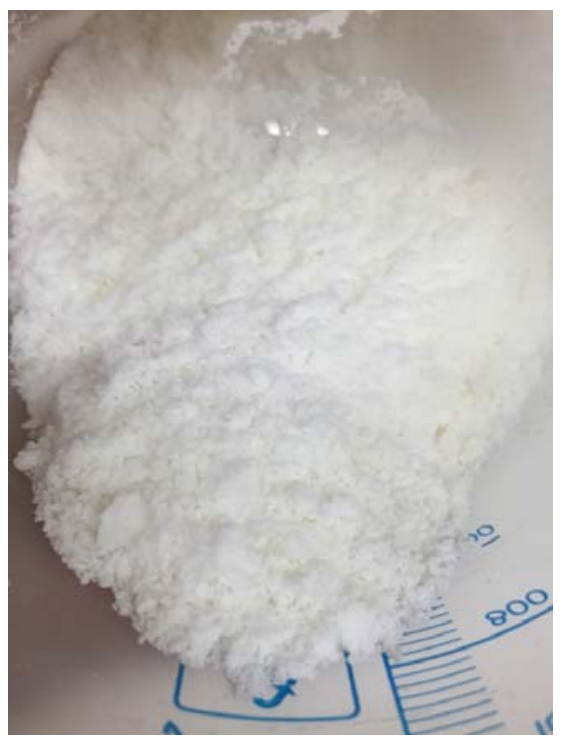

FIGURE 20 Mixture of $\mathrm{NH}_{4} \mathrm{Cl}$ and $\left(\mathrm{NH}_{4}\right)_{6} \mathrm{Mo}_{7} \mathrm{O}_{24} \cdot \mathrm{xH}_{2} \mathrm{O}$ after Evaporation of $\mathrm{NH}_{4} \mathrm{OH}$ from Mo Strip Solution. 
The $\mathrm{NH}_{4} \mathrm{Cl}$ was removed from the product using $80 \%$ ethanol wash; $580 \mathrm{~g}$ of the $\mathrm{NH}_{4} \mathrm{Cl}$ and $\left(\mathrm{NH}_{4}\right)_{6} \mathrm{Mo}_{7} \mathrm{O}_{24} \cdot \mathrm{xH}_{2} \mathrm{O}$ mixture was obtained after rotary evaporation of the strip solution. The solid was contacted with $80 \%$ ethanol and mixed using overhead mixer. Usually, $\sim 1 \mathrm{~L}$ of $80 \%$ ethanol was used per $60 \mathrm{~g}$ of $\mathrm{NH}_{4} \mathrm{Cl}$ and $\left(\mathrm{NH}_{4}\right)_{6} \mathrm{Mo}_{7} \mathrm{O}_{24} \cdot \mathrm{xH}_{2} \mathrm{O}$ mixture. After the first wash, $\sim 280 \mathrm{~g}$ of air dried solid containing Mo was recovered and washed twice more with $1 \mathrm{~L}$ of fresh $80 \%$ ethanol. The solid was air dried, and $247.7 \mathrm{~g}$ of ammonium molybdate was recovered. Based on these results, the composition of the solid after evaporation of strip solution is $\sim 43 \%$ $\left(\mathrm{NH}_{4}\right)_{6} \mathrm{Mo}_{7} \mathrm{O}_{24} \cdot \mathrm{XH}_{2} \mathrm{O}$ and $57 \% \mathrm{NH}_{4} \mathrm{Cl}$. Note that if TCE were used instead of 1-octanol as a diluent for TBP, the amount of $\mathrm{NH}_{4} \mathrm{Cl}$ in the strip solution would be significantly lower. Based on ICP-MS analysis, $247.7 \mathrm{~g}$ of ammonium molybdate contains $125.2 \mathrm{~g}$ of Mo, which gives $\sim 50.6 \%$ content of Mo, somewhat lower than the $54.3 \%$ theoretical content of Mo in $\left(\mathrm{NH}_{4}\right)_{6} \mathrm{Mo}_{7} \mathrm{O}_{24} \cdot 4 \mathrm{H}_{2} \mathrm{O}$. This difference could be due to some presence of $\mathrm{NH}_{4} \mathrm{Cl}$ or not sufficiently dried salt.

The $248 \mathrm{~g}$ of ammonium molybdate was then heated at $500^{\circ} \mathrm{C}$ to produce $\mathrm{MoO}_{3}$

$$
\left(\mathrm{NH}_{4}\right)_{6} \mathrm{Mo}_{7} \mathrm{O}_{24} \cdot 4 \mathrm{H}_{2} \mathrm{O} \rightarrow 7 \mathrm{MoO}_{3}+6 \mathrm{NH}_{3}+7 \mathrm{H}_{2} \mathrm{O}
$$

Table 9 shows the concentration of various elements in various stages of the solvent extraction process determined by ICP-MS.

A significant amount of $\mathrm{K}$ was removed by acidifying the spent generator solution with $\mathrm{HCl}$ before solvent extraction. The starting solution has $\sim 9.4 \mathrm{~g}-\mathrm{Na} / \mathrm{kg}-\mathrm{Mo}$, which is most likely due to the presence of $\mathrm{Na}$ in the potassium hydroxide used after dissolution of the sintered Mo disks. The Na concentration was reduced to $\sim 9.3 \mathrm{ppm}$ in the recycled $\mathrm{MoO}_{3}$, which is acceptably low. Also a significant amount of $\mathrm{Cu}$ and $\mathrm{W}$ was removed. As confirmed by the tracer study (Section 2.1.5), $\mathrm{Zr}$ does not follow Mo, and its concentration in the $\mathrm{MoO}_{3}$ product was below the detection limit. On the other hand, $\mathrm{Nb}$ extracts relatively well (also confirmed by the tracer study in Section 2.1.5), and no significant purification was observed under the conditions used. The high phosphorus concentration in the $\mathrm{NH}_{4} \mathrm{OH}$ strip is due to some carryover of organic phase containing TBP into the strip phase, which can be minimized by washing the strip solution with octanol. Table 9 also shows that phosphorus is removed during the $80 \% \mathrm{EtOH}$ wash of ammonium molybdate (when $\mathrm{NH}_{4} \mathrm{Cl}$ is removed), and the concentration of phosphorus in the recovered $\mathrm{MoO}_{3}$ product was below the detection limit. The separation factors (SFs) in the last column of Table 9 show the ratio of the concentration of the element in the feed solution before extraction and in the final Mo product. The lowest SFs were obtained for Nb, W, Ti, Sn, and Zn. As discussed in Section 2.1.5, $\mathrm{Nb}$ could be potentially removed by optimizing the scrub section, as $\mathrm{D}(\mathrm{Nb})$ is significantly lower from $<4 \mathrm{M} \mathrm{HCl}$. Tin is being introduced during the dissolution (used as stabilizer in $50 \% \mathrm{H}_{2} \mathrm{O}_{2}$ ), so similarly as for $\mathrm{Nb}$, we will explore if optimizing the scrubbing section of the extraction process could improve removal of Sn. The concentrations of $\mathrm{W}$ and $\mathrm{Zn}$ in the enriched material are very low, so their starting concentration would be significantly lower and should not cause any problem due to activation. Also worth noting is that the SF will be significantly improved if several extraction stages are implemented with a centrifugal contactor setup. 


\section{TABLE 9 Concentration of Various Elements in Different Stages of Solvent Extraction Process Using TBP}

\begin{tabular}{|c|c|c|c|c|c|c|}
\hline \multirow[b]{2}{*}{ Element } & \multicolumn{5}{|c|}{ Conc., ppm (mg/kg-Mo) } & \multirow[b]{2}{*}{$\mathrm{SF}$} \\
\hline & $\begin{array}{l}\text { Mo in } \\
\mathrm{KOH}\end{array}$ & $\begin{array}{l}\mathrm{HCl} \text { phase } \\
\text { Before } \\
\text { Extraction }\end{array}$ & $\begin{array}{c}\text { Strip } \\
\text { Phase, } \\
\mathrm{NH}_{4} \mathrm{OH}\end{array}$ & $\begin{array}{c}\text { Solid Molybdate } \\
\text { After Etoh/Water } \\
\text { Wash }\end{array}$ & $\begin{array}{c}\mathrm{MoO}_{3} \text { After } \\
\text { Conversion } \\
\text { from Molybdate }\end{array}$ & \\
\hline B & ND & ND & 2 & 9.1 & ND & ND \\
\hline $\mathrm{Na}$ & 9439 & 9712 & 24.7 & 10.9 & 9.3 & 1015 \\
\hline $\mathrm{Mg}$ & 29.6 & 21.7 & 4.8 & 4 & 5.1 & 6 \\
\hline $\mathrm{Al}$ & 8.3 & 8.46 & 2.8 & ND & ND & ND \\
\hline $\mathrm{Si}$ & ND & ND & ND & ND & ND & ND \\
\hline $\mathrm{P}$ & ND & ND & 1838 & ND & ND & ND \\
\hline $\mathrm{Ti}$ & 26.7 & 64.1 & 37.3 & 13.7 & 12.4 & 2 \\
\hline $\mathrm{Cr}$ & ND & 0 & 5.2 & ND & ND & ND \\
\hline $\mathrm{Mn}$ & 1.9 & 0.55 & 0.4 & ND & ND & ND \\
\hline $\mathrm{Fe}$ & ND & ND & ND & ND & ND & ND \\
\hline Co & ND & ND & ND & ND & ND & ND \\
\hline $\mathrm{Ni}$ & ND & ND & 0.8 & ND & ND & ND \\
\hline $\mathrm{Cu}$ & 5255 & 7.7 & 23.3 & ND & 7.8 & 674 \\
\hline $\mathrm{Zn}$ & 12.4 & ND & 24.6 & 2.4 & 3.1 & 4 \\
\hline $\mathrm{Zr}$ & 0.6 & 0.37 & 0.1 & ND & ND & ND \\
\hline $\mathrm{Nb}$ & 2.8 & 1.53 & 1.5 & 2.9 & 2.7 & 1 \\
\hline $\mathrm{Sn}$ & 86.2 & 19.2 & 22.3 & 24 & 20.5 & 4 \\
\hline $\mathrm{Sb}$ & 4.7 & 4.1 & 4.2 & ND & ND & ND \\
\hline $\mathrm{Cs}$ & 0.8 & 0.66 & 0.7 & 0.2 & 0.1 & 8 \\
\hline W & 237 & 259 & 138 & 164 & 159 & 1 \\
\hline $\mathrm{K}$ & 1933673 & 1217949 & 454 & 257 & 233 & 8299 \\
\hline $\mathrm{K}(\%)$ & $100 \%$ & $63.00 \%$ & $0.02 \%$ & $0.01 \%$ & $0.01 \%$ & \\
\hline
\end{tabular}

ND - not detected.

SF- separation factor, i.e., concentration in feed/concentration in product.

If needed, ethanol can be purified/recycled by rotary evaporation. After evaporation of ethanol, solid containing $\mathrm{NH}_{4} \mathrm{Cl}$ and a small portion of organics such as TBP and the diluent can be disposed as waste.

After combining recycled Mo material, we sent $\sim 500 \mathrm{~g}$ of $\mathrm{MoO}_{3}$ to ORNL for reduction to Mo metal powder. However, the produced $\mathrm{MoO}_{2}$ and Mo powder had a particle size of only few micrometers, and the material was not suitable for production of spray-dried sintered Mo disks. Therefore, we initiated experiments focused on optimizing the particle size of $\mathrm{MoO}_{3}$, and preliminary results are discussed in Section 5.

These large-scale experiments showed that the solvent extraction process could also be adopted as a batch process, although an automated process using centrifugal contactors has many benefits. Very good purification from potassium and other elements was observed with very 
good recovery yields ( $\sim 98 \%)$. Compared to the previously developed recycle process, where acetic acid is used to precipitate Mo, solvent extraction can provide a much better purification factor for potassium and many other elements. Moreover, the organic solvent can be recycled, significantly minimizing the amount of waste produced. Although the particle size of recycled $\mathrm{MoO}_{3}$ did not meet the criteria for production of spray-dried sintered Mo disks, experiment are underway to optimize the process of conversion from ammonium molybdate to produce $\mathrm{MoO}_{3}$ with larger particle size. 


\section{PROCESS FOR PARTICLE SIZE CONTROL OF MOLYBDENUM OXIDE}

Based on requirements from ORNL, the goal of this project is to produce $\mathrm{MoO}_{3}$ powder with a particle size range of 50 to $200 \mu \mathrm{m}$. Ultimately, the goal is to produce Mo metal powder with a particle size of 1-10 $\mu \mathrm{m}$, with the majority having sizes of about $5 \mu \mathrm{m}$.

The particle size of the currently produced $\mathrm{MoO}_{3}$ is too small, resulting in Mo powder that is too fine to properly sinter and press into the desired target. The process from $\mathrm{MoO}_{3}$ to the final form has been shown to work with commercial $\mathrm{MoO}_{3}$ of 50-200 $\mu \mathrm{m}$ particle size.

The current recycling process provides ammonium heptamolybdate, $\left(\mathrm{NH}_{4}\right)_{6} \mathrm{Mo}_{7} \mathrm{O}_{24}$, with particle size of 200-300 $\mu \mathrm{m}$. This material is currently converted to $\mathrm{MoO}_{3}$ by simple heat treatment (oven at $300-500^{\circ} \mathrm{C}$ ). There is some indication of particle size growth at $650^{\circ} \mathrm{C}$, but at this temperature, $\mathrm{MoO}_{3}$ is also significantly volatile, and material is lost.

\subsection{PARTICLE-SIZE DEPENDENCE OF $\mathrm{MoO}_{3}$ ON RECYCLED $\left(\mathrm{NH}_{4}\right)_{6} \mathrm{Mo}_{7} \mathrm{O}_{24}$ POWDER}

The particle size of the ammonium heptamolybdate (AHM) powder needs to be determined to further direct the project. If the particles are sufficiently large, then controlled heating ramps may allow large enough particles of $\mathrm{MoO}_{3}$ powder to be made directly. However, if the AHM powder is already less than $50 \mu \mathrm{m}$, there is likely no way to increase the particle size by heating. At this point, sublimation of the $\mathrm{MoO}_{3}$ powder will be required. This measurement will be accomplished by SEM and particle size distribution (PSD) analysis. Thermogravimetric analysis (TGA) will be used to assess the effect of the heating rate and final temperatures on the PSD of $\mathrm{MoO}_{3}$, and to determine the minimum required lower limit of AHM particle size. This will be accomplished using several different lots (large and smaller particle sizes) of AHM.

Samples of AHM (molecular weight of $1235.86 \mathrm{~g} / \mathrm{mol}$ ) and Mo(VI) oxide were obtained from commercial sources, and one sample from previous studies in the Nuclear Engineering Division (NE):

1. Sample 1: Ammonium heptamolybdate, Sigma Aldrich, \#09878-5, $>99 \%$ purity, $1235.86 \mathrm{~g} / \mathrm{mol}$, Lot \# BCBN3120V

2. Sample 2: Ammonium heptamolybdate, Acros Organics, \#423310050, ACS reagent, $1235.86 \mathrm{~g} / \mathrm{mol}$, Lot \#A0322224

3. Sample 3: Ammonium heptamolybdate, Alfa Aesar, \#A13766, 99\%, $1235.86 \mathrm{~g} / \mathrm{mol}$, Lot \# 10181023

4. Sample 4: Ammonium heptamolybdate, TKAC-NE-2-7542, Dated 07/17/15, $1235.86 \mathrm{~g} / \mathrm{mol}$ 
5. Sample 5: Mo(VI) oxide, Alfa Aesar, A11159, Lot\# R20B041

The TGA for samples 1-4 was performed with a heating rate of $10^{\circ} \mathrm{C} / \mathrm{min}$ to $500^{\circ} \mathrm{C}$ under air at a flow rate of $50 \mathrm{ml} / \mathrm{min}$. Analysis by SEM was conducted on the samples before and after the TGA test. Figure 21 displays the SEM images of Sample 1. Figure 22 shows the TGA and the differential scanning calorimetry (DSC - the difference in the amount of heat required to increase the temperature) for Sample 1.

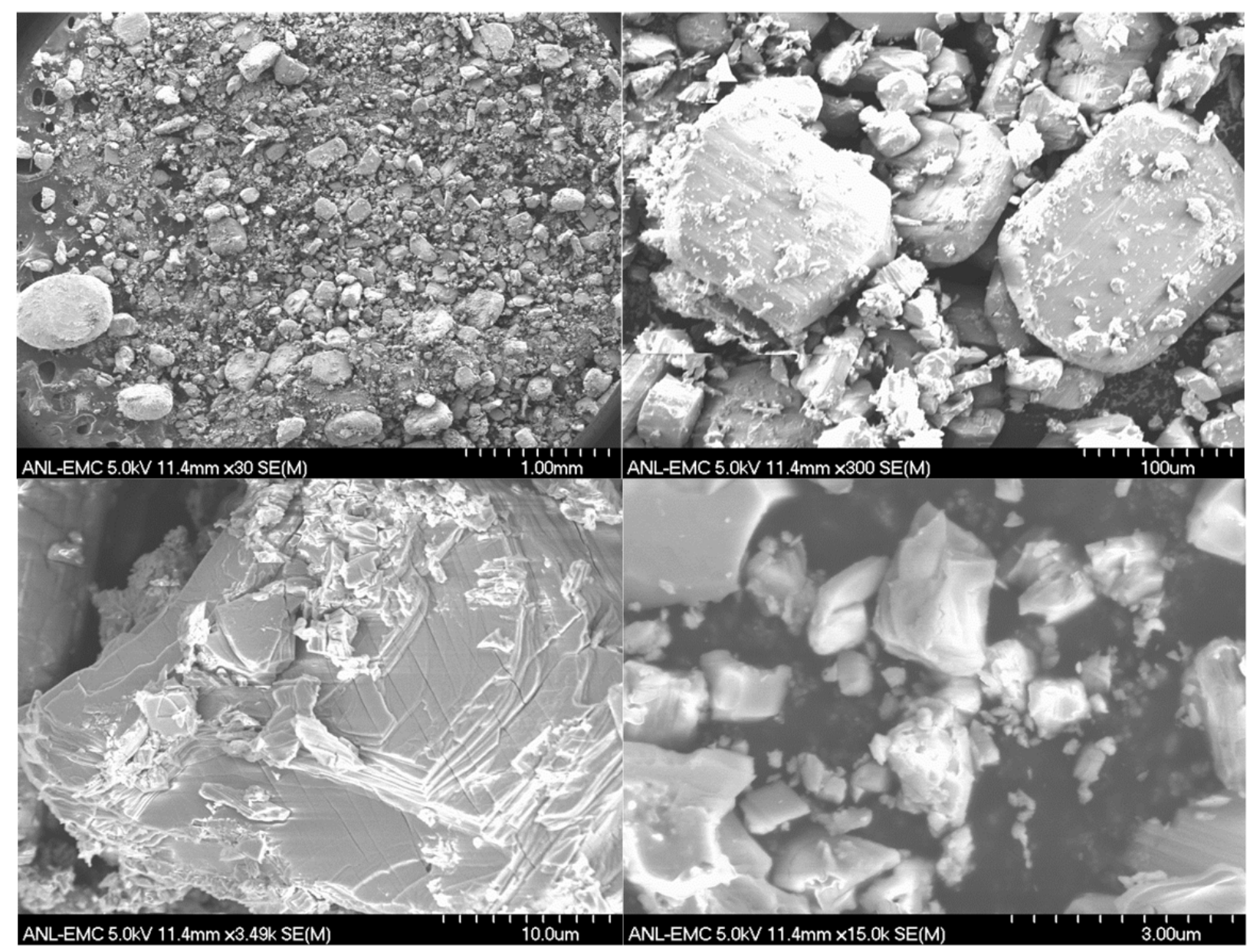

FIGURE 21 SEM Images of Ammonium Molybdate Crystals as Received from Supplier (Sample 1, Sigma). Particle sizes have a relatively broad distribution from large aggregates measuring $1 \mathrm{~mm}$ to as small as $0.5 \mu \mathrm{m}$. 

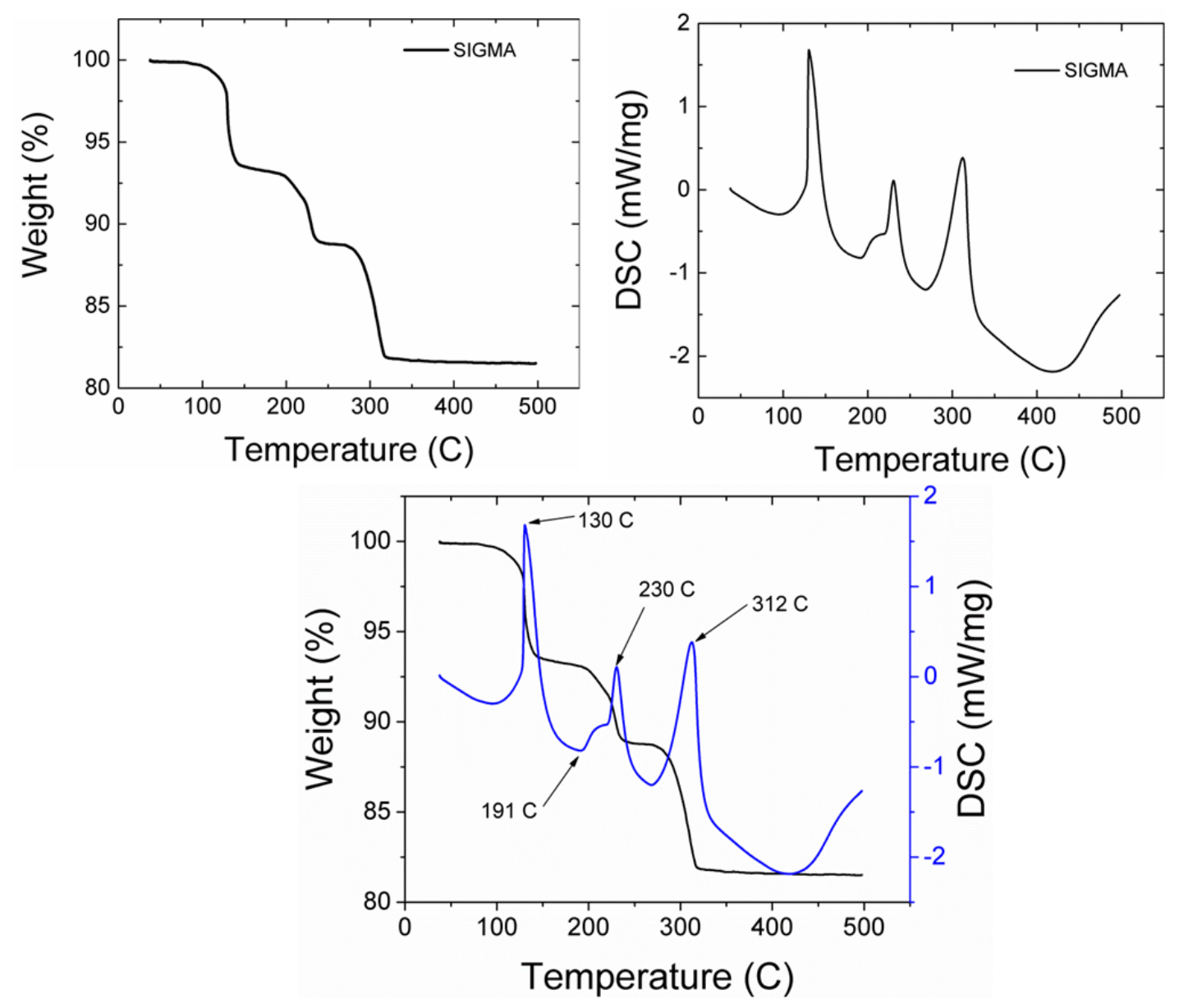

FIGURE 22 (a) TGA of Ammonium Molybdate Crystals as Received from Supplier (Sample 1), (b) DSC Analysis during Same Test, and (c) Overlay of DSC and TGA

The thermal decomposition of the AHM in air seen in Figure 22 is consistent with the literature [9]. There is a continuous mass loss up to $300^{\circ} \mathrm{C}$. Beyond this temperature, the mass of the treated sample is stabilized up to $500^{\circ} \mathrm{C}$. The mass loss caused by thermal treatment was $18.4 \%$. This loss is due to the decomposition of the $\mathrm{AHM}$ to $\mathrm{MoO}_{3}$ and the removal of ammonia and water molecules (Eq. 9).

Four distinct mass loss steps are visible in Figure 22a, accompanied by endothermic peaks. The first mass loss was observed between 80 and $140^{\circ} \mathrm{C}$, with a strong endothermic peak assigned to the loss of weakly bonded water molecules. The second and third mass-loss steps were observed between 180 and $250^{\circ} \mathrm{C}$ with an endothermic peak at $230^{\circ} \mathrm{C}$ and an accompanying shoulder at $191-210^{\circ} \mathrm{C}$. This process is assigned to the evolution of structurally intercalated crystalline water and ammonia, respectively. A fourth mass-loss step begins at $260^{\circ} \mathrm{C}$ ending at $330^{\circ} \mathrm{C}$, with a strong endothermic peak at $312^{\circ} \mathrm{C}$ associated with the loss of a large proportion of crystalline water and ammonium ions. Further heating to $500^{\circ} \mathrm{C}$ does not reveal any further mass loss, but a change in heat flow is observed in the DSC. This needs to be validated by further testing before in depth analysis. Figure 23 presents SEM images following the TGA of Sample 1. 


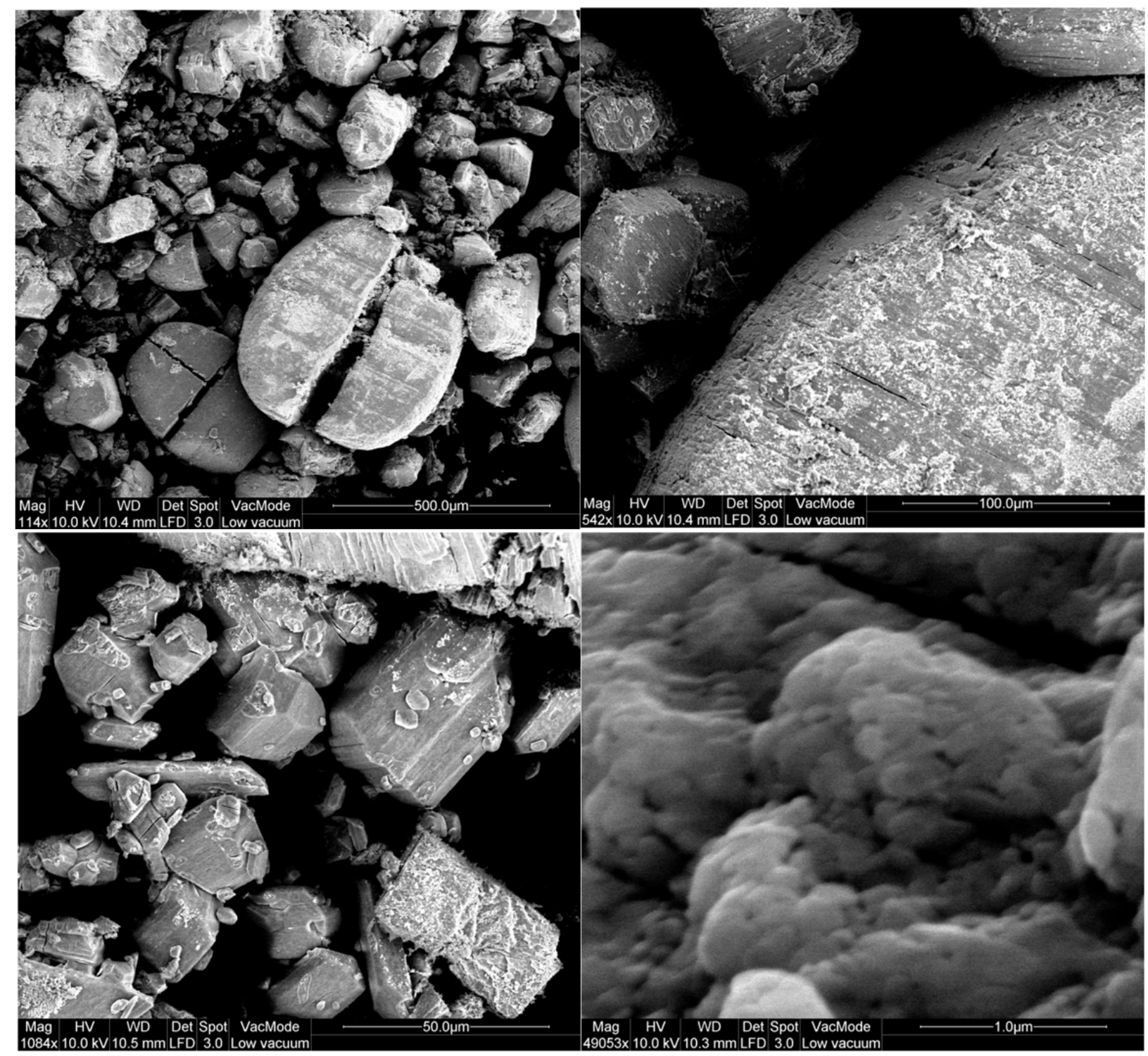

FIGURE 23 SEM Images of Calcined Powder after TGA Test (Sample 1, Sigma). Particle sizes remain within a relatively broad range from $500 \mu \mathrm{m}$ to $1 \mu \mathrm{m}$. High magnification images of the surface of the aggregates show submicron particles fused together

Figures 24-26 present SEMs of Sample 2 as received, the TGA results, and SEMs following the TGA. Figures 27-32 present corresponding images for Samples 3 and 4. Figure 33 shows SEM images for the commercially obtained $\mathrm{MoO}_{3}$ (Sample 5). The TGA and DSC results for all four AHM samples are graphed together in Figure 34.

Additionally, sample 1 (Sigma) and sample 4 (NE) were heated to $500^{\circ} \mathrm{C}$ under air for $30 \mathrm{~min}$ and $1 \mathrm{~h}$, respectively, in a muffle furnace using alumina crucibles to determine the compatibility of the materials involved. The SEM images for the heat treated products are shown in Figures 35 and 36. No adverse reaction occurred with the crucible. 


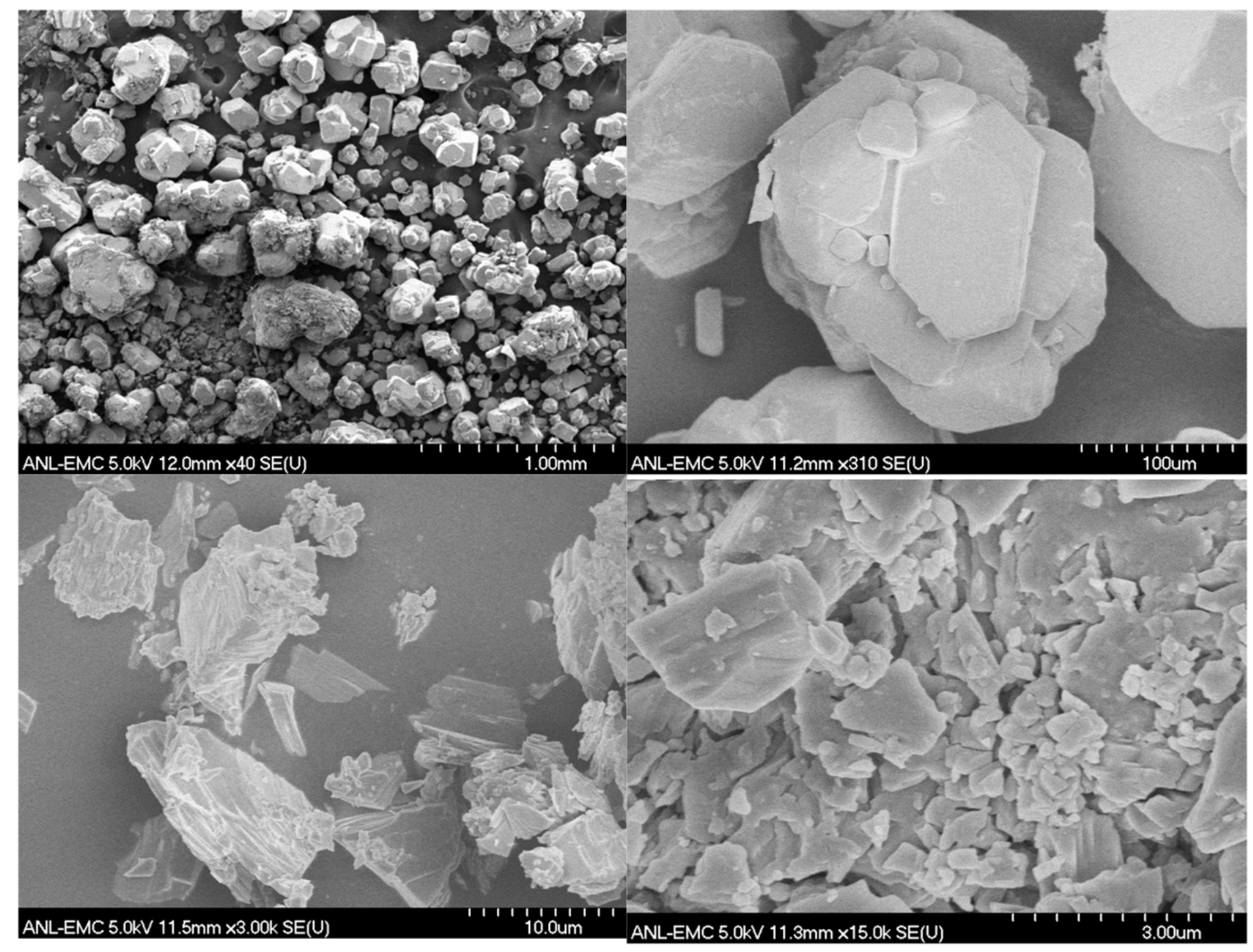

FIGURE 24 SEM Images of Ammonium Molybdate Crystals as Received from Supplier (Sample 2, Acros). Significant number of particles is in the 100-200 $\mu \mathrm{m}$ range. However, it also contains smaller particles in the $0.5-10 \mu \mathrm{m}$ range.
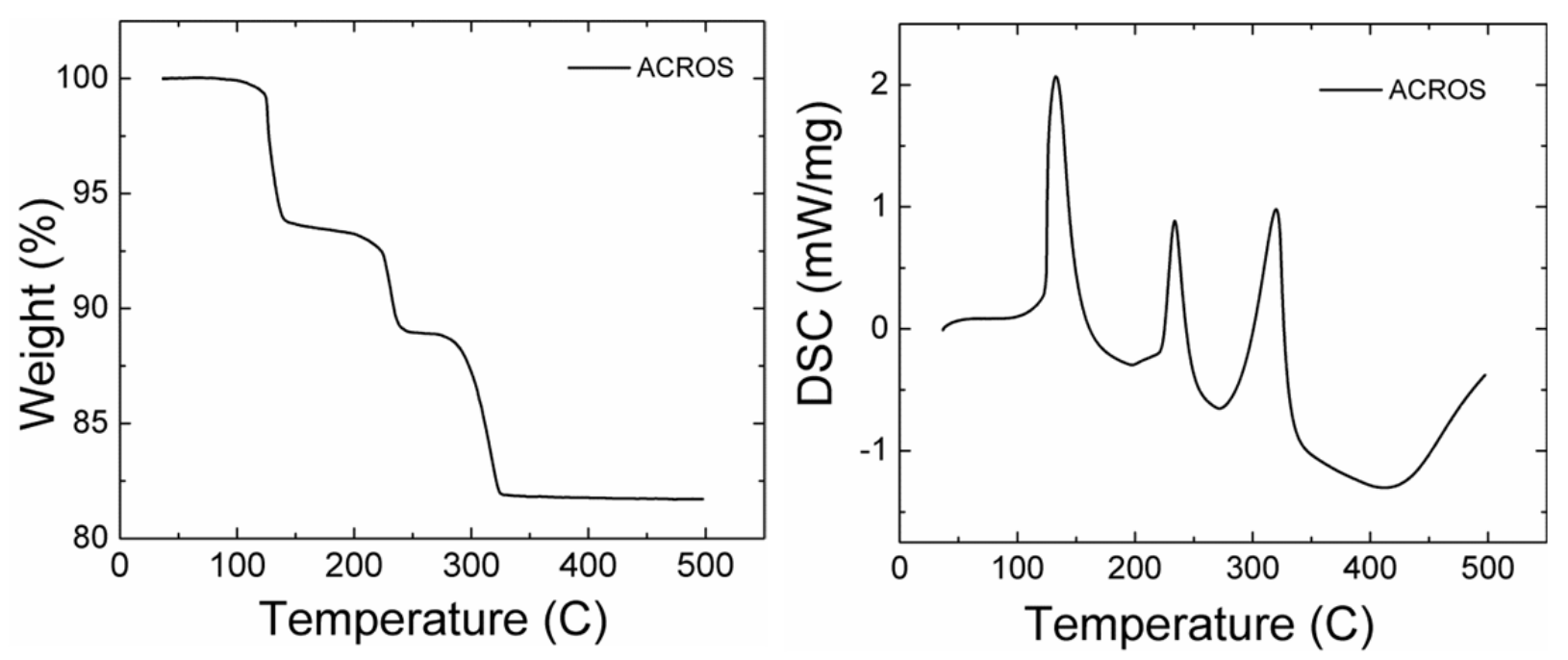

FIGURE 25 (a) TGA of Ammonium Molybdate Crystals as Received from Supplier (Sample 2) and (b) DSC Analysis during Same Test 


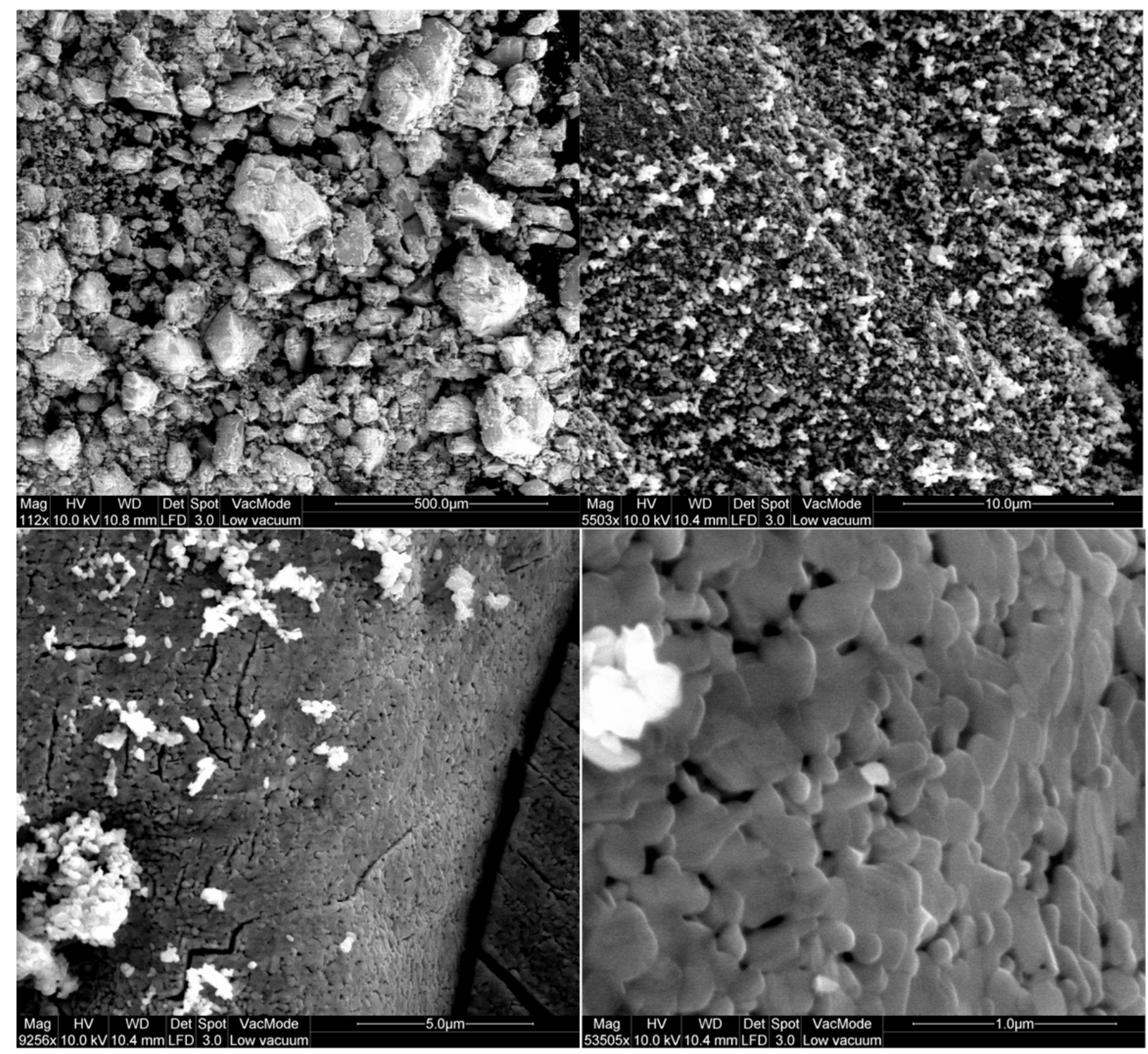

FIGURE 26 SEM Images of Calcined Powder after TGA Test (Sample 2, Acros). Particle sizes have a relatively broad distribution from large aggregates measuring $0.5 \mathrm{~mm}$ to as small as $0.5 \mu \mathrm{m}$. High magnification images of the surface of the aggregates show submicron particles fused together. 


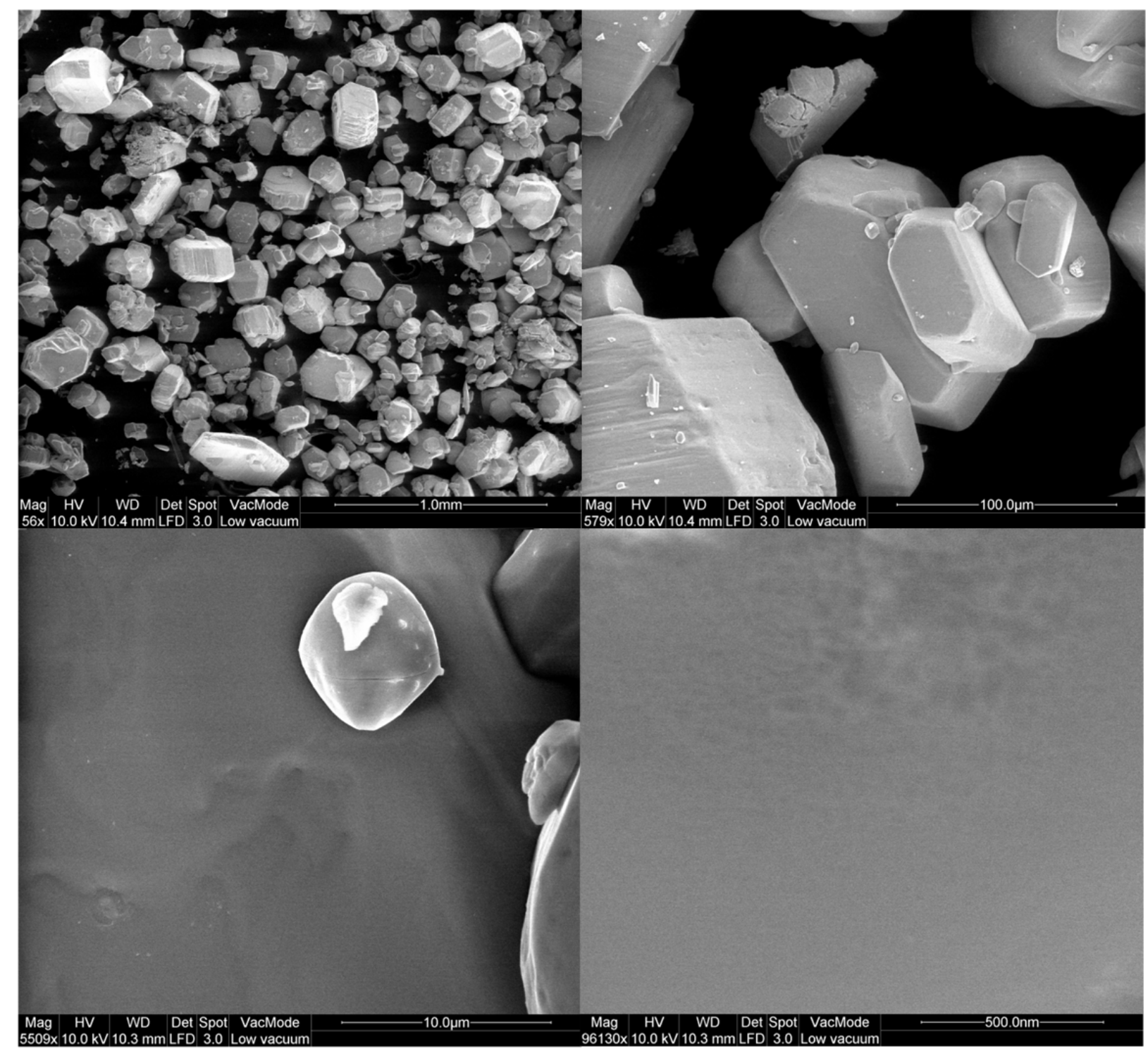

FIGURE 27 SEM Images of Ammonium Molybdate Crystals as Received from Supplier (Sample 3, Alfa). Significant number of particles are in the 100-200 $\mathrm{\mu m}$ range with relatively few particles in 1-10 $\mu \mathrm{m}$ range. 

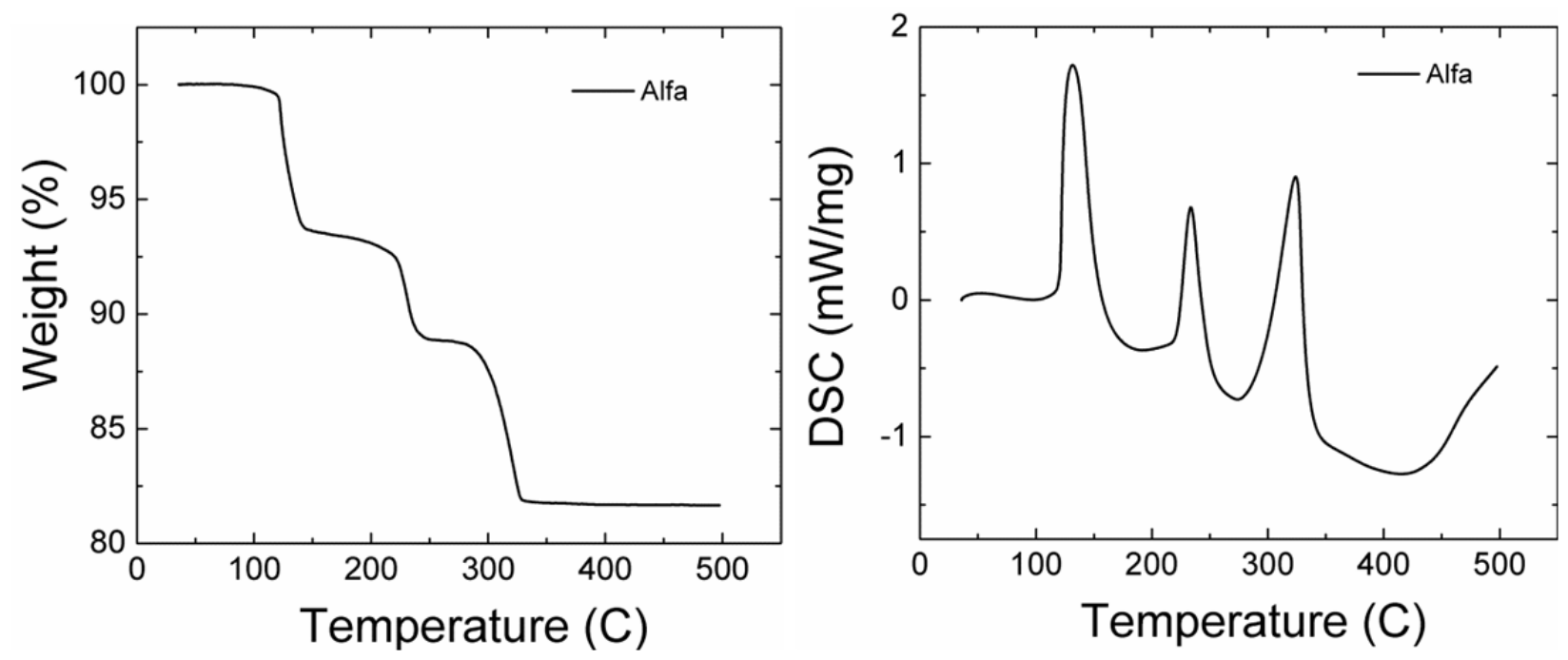

FIGURE 28 (a) TGA of Ammonium Molybdate Crystals as Received from Supplier (Sample 3) and (b) DSC Analysis during Same Test 


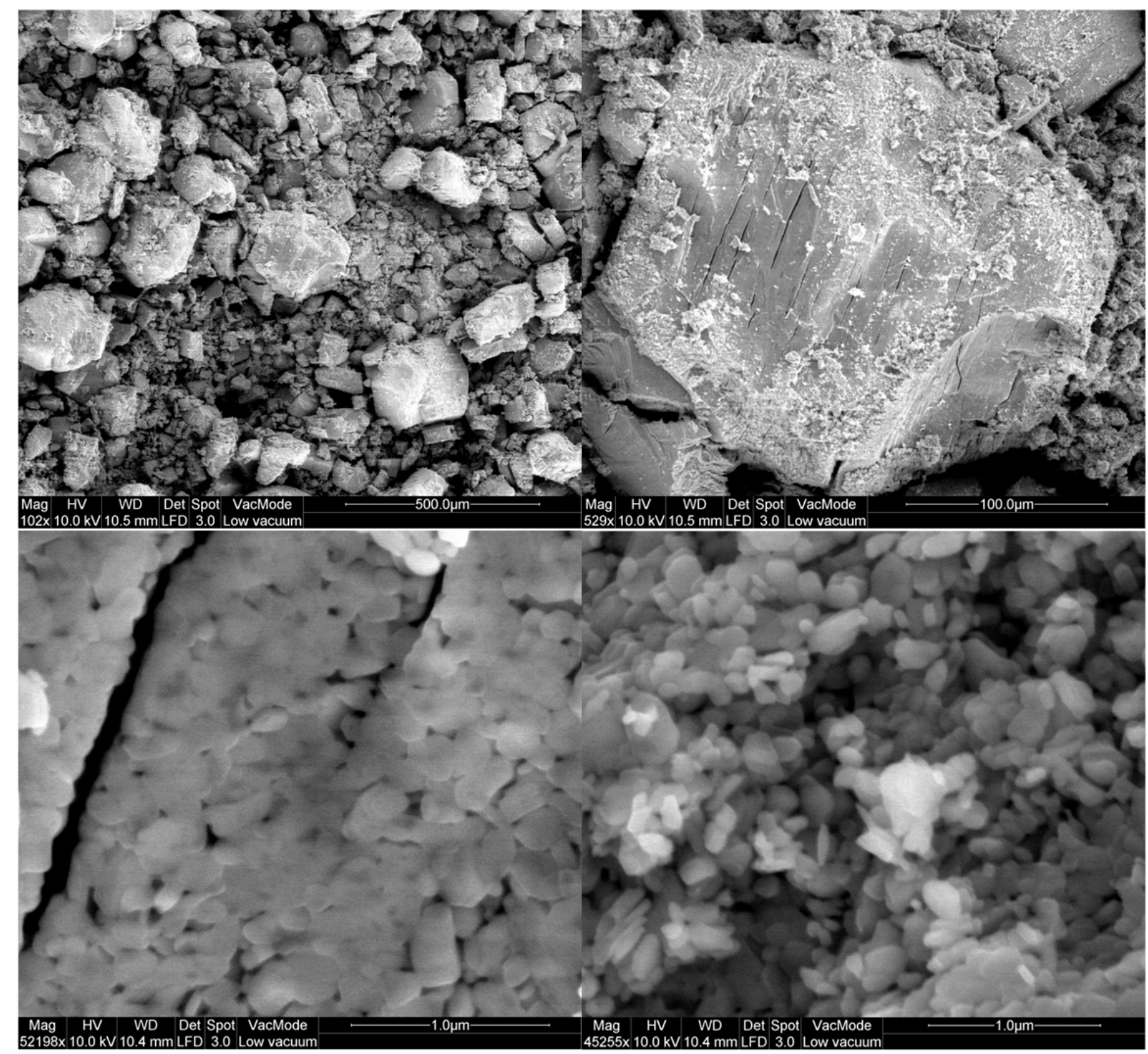

FIGURE 29 SEM Images of Calcined Powder after TGA Test (Sample 3, Alfa). Particle sizes are varied with a mixture of submicron-free particles attached to the surface of larger aggregates. High magnification images of the surface of the aggregates show submicron particles fused together. 


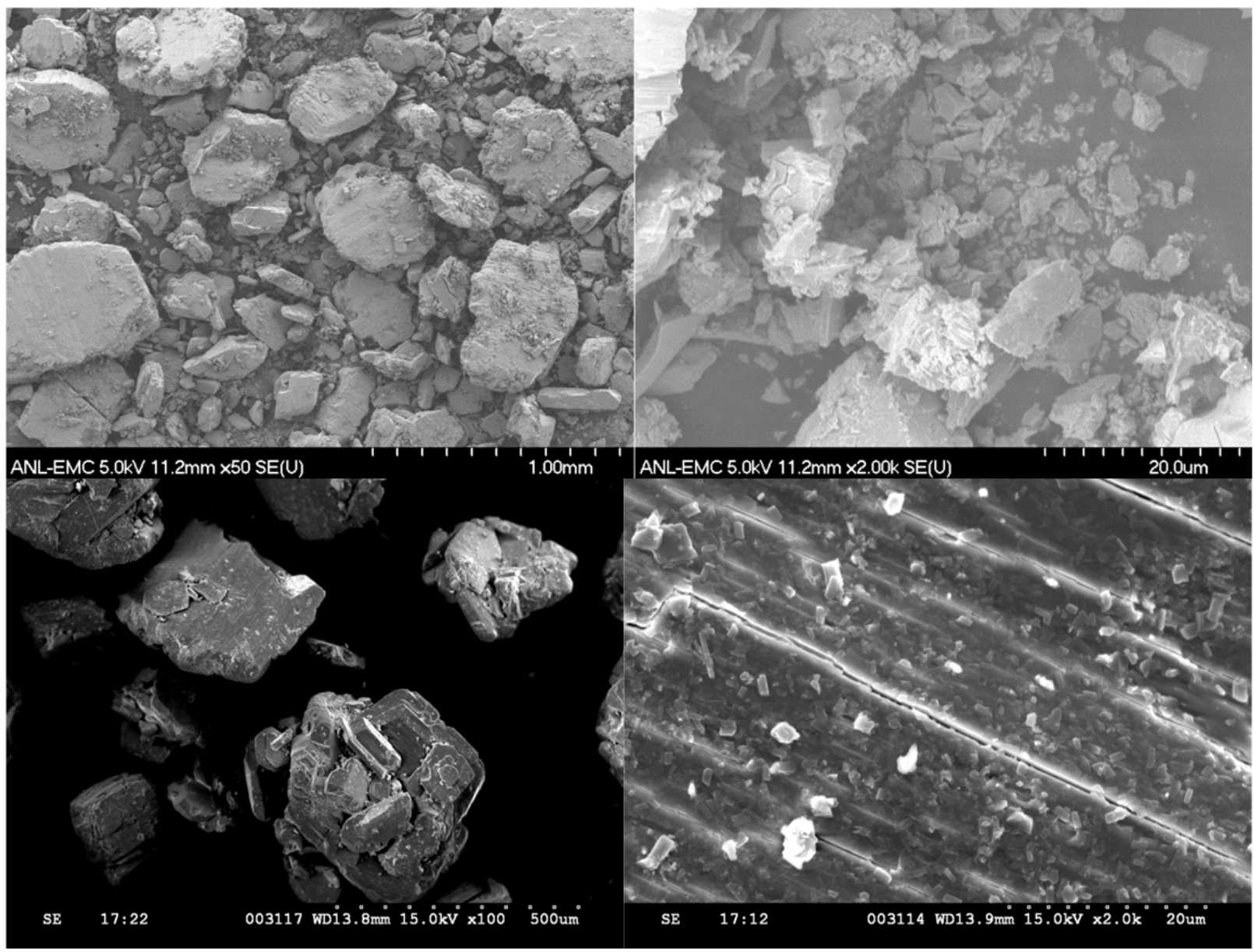

FIGURE 30 SEM Images of Ammonium Molybdate Crystals Recycled from Solvent Extraction Process (Sample 4, NE). Significant number of particles are in the 200-500 $\mathrm{\mu m}$ range. However, it also contains smaller particles in the $0.5-10 \mu \mathrm{m}$ range.
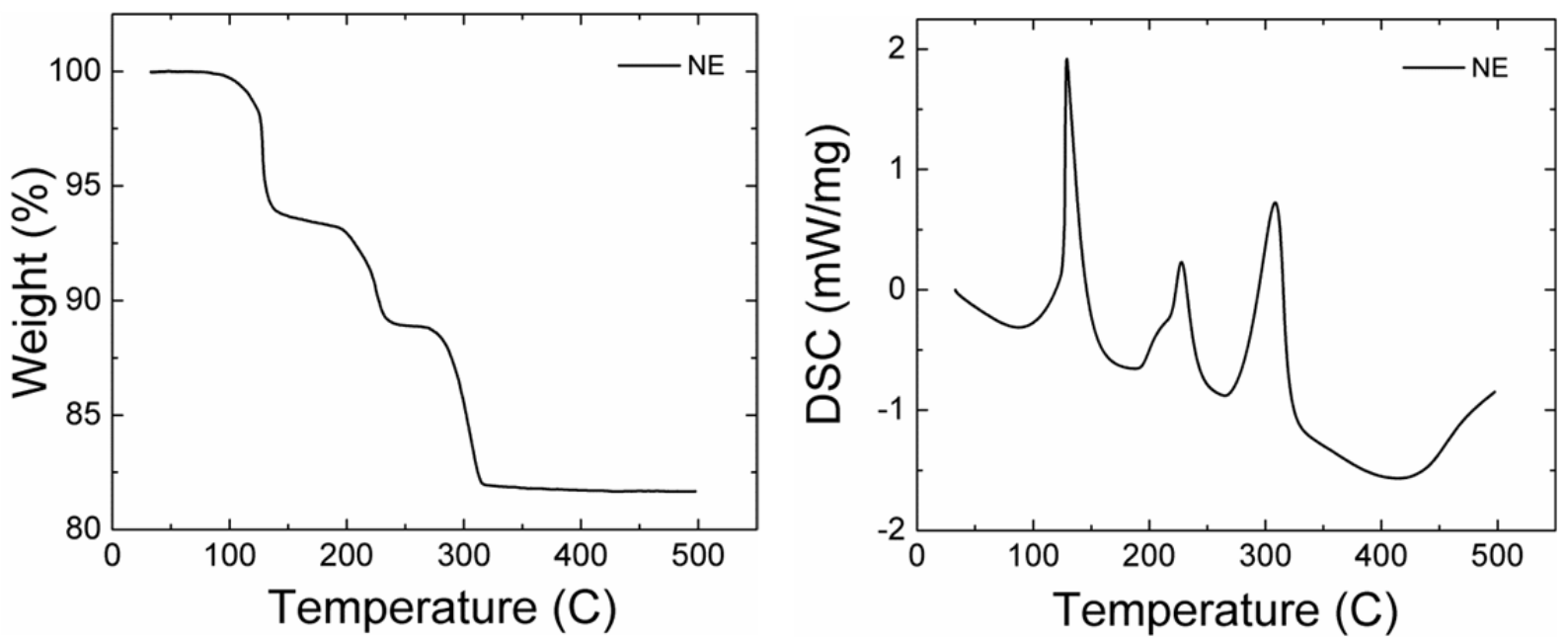

FIGURE 31 (a) TGA of Ammonium Molybdate Crystals as Received and Recycled from Solvent Extraction Process (Sample 4-NE) and (b) DSC Analysis during Same Test 


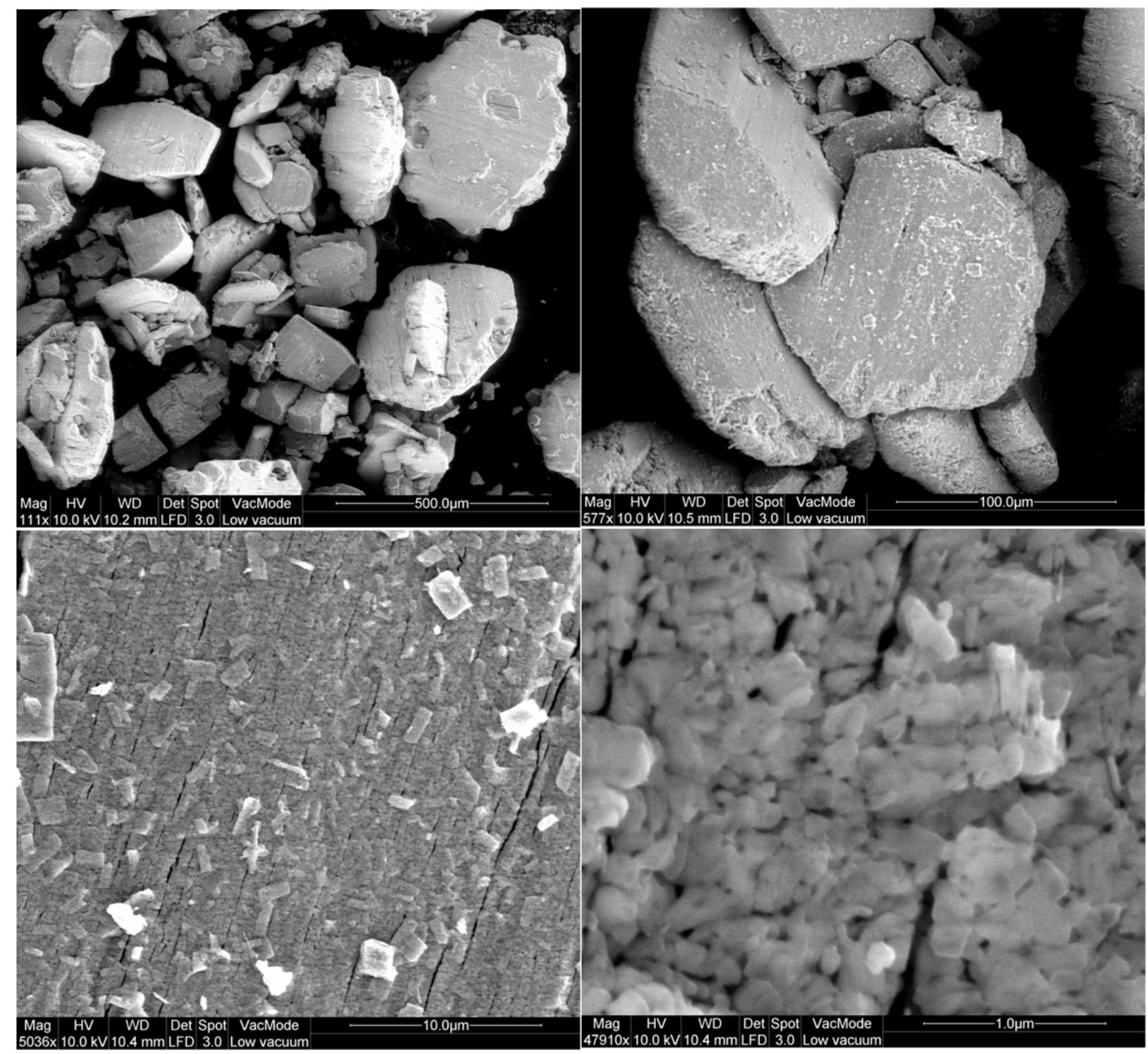

FIGURE 32 SEM Images of Calcined Recycled Powder from Solvent Extraction Process after TGA Test (Sample 4-NE). Particle sizes remain largely in the 100-200 $\mathrm{\mu m}$ range. Submicron particles attached to the surface of larger aggregates are observable. High magnification images of the surface of the aggregates show submicron particles fused together. 


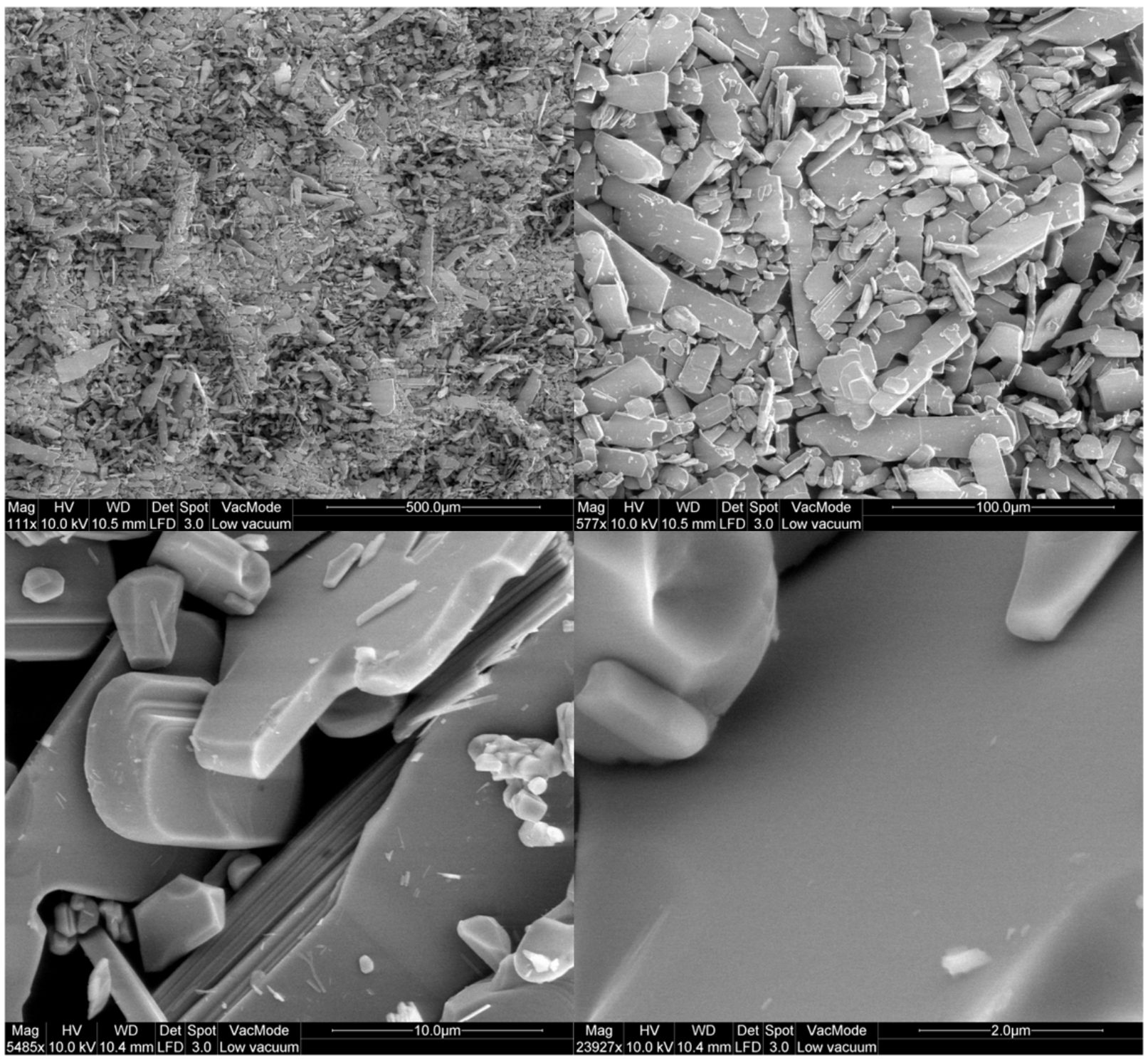

FIGURE 33 SEM Images of Molybdenum (VI) Oxide Crystals as Received (Sample 5, Alfa). General "flake" type morphology is distinctly different from the previous samples (1-4) before and calcination in the TGA test. It has a broad distribution of rectangular and irregularly shaped flakes. No discernible nanostructure is observed at high magnification. 

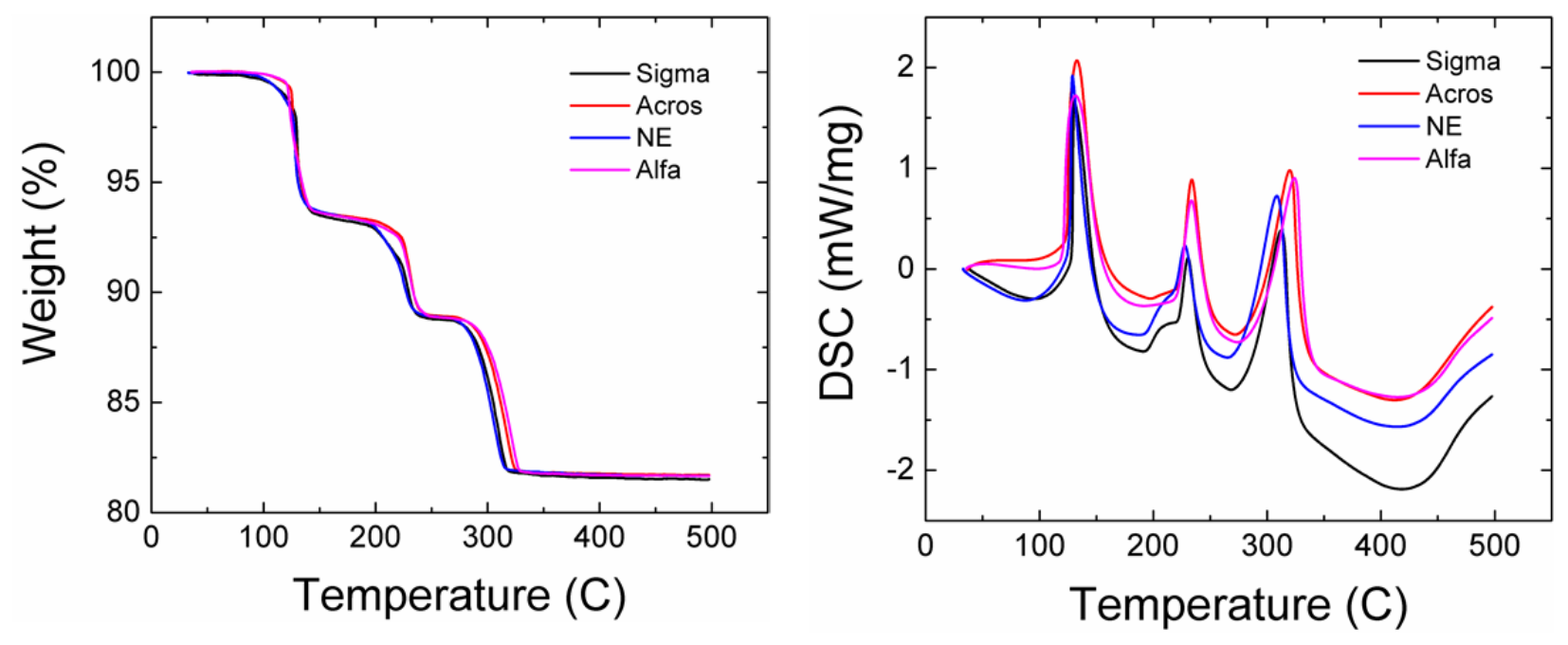

FIGURE 34 (a) TGA of Ammonium Heptamolybdate Crystals (Samples 1-4) as Received from Various Suppliers and (b) DSC Analysis during Same Test

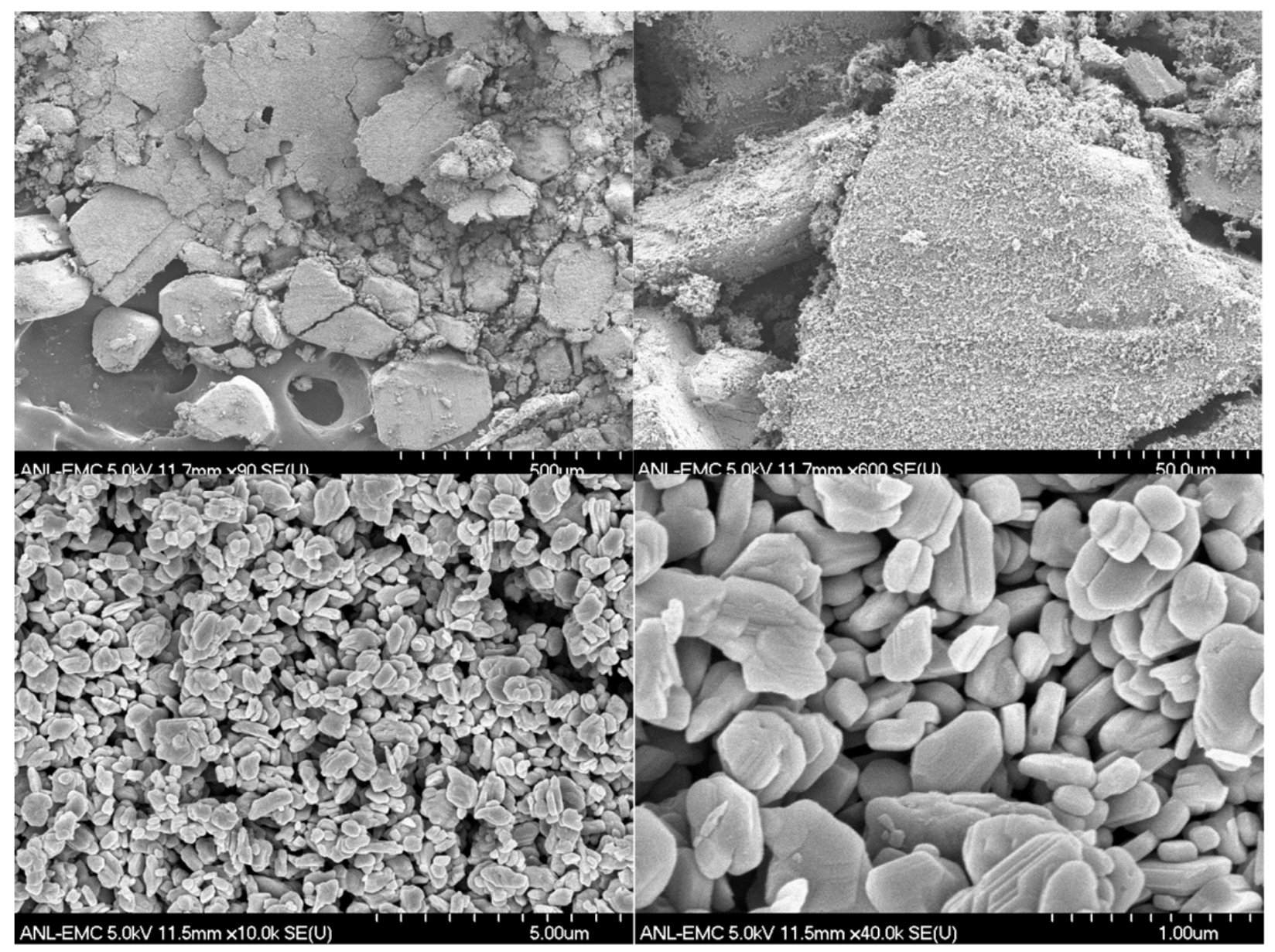

FIGURE 35 SEM Images of Sample 1 (Sigma) after Calcination at $500^{\circ} \mathrm{C}$ for 30 Minutes. Large aggregates are present, but they consist of distinct micron and sub-micron particles of $\mathrm{MoO}_{3}$ (to be confirmed with XRD). 


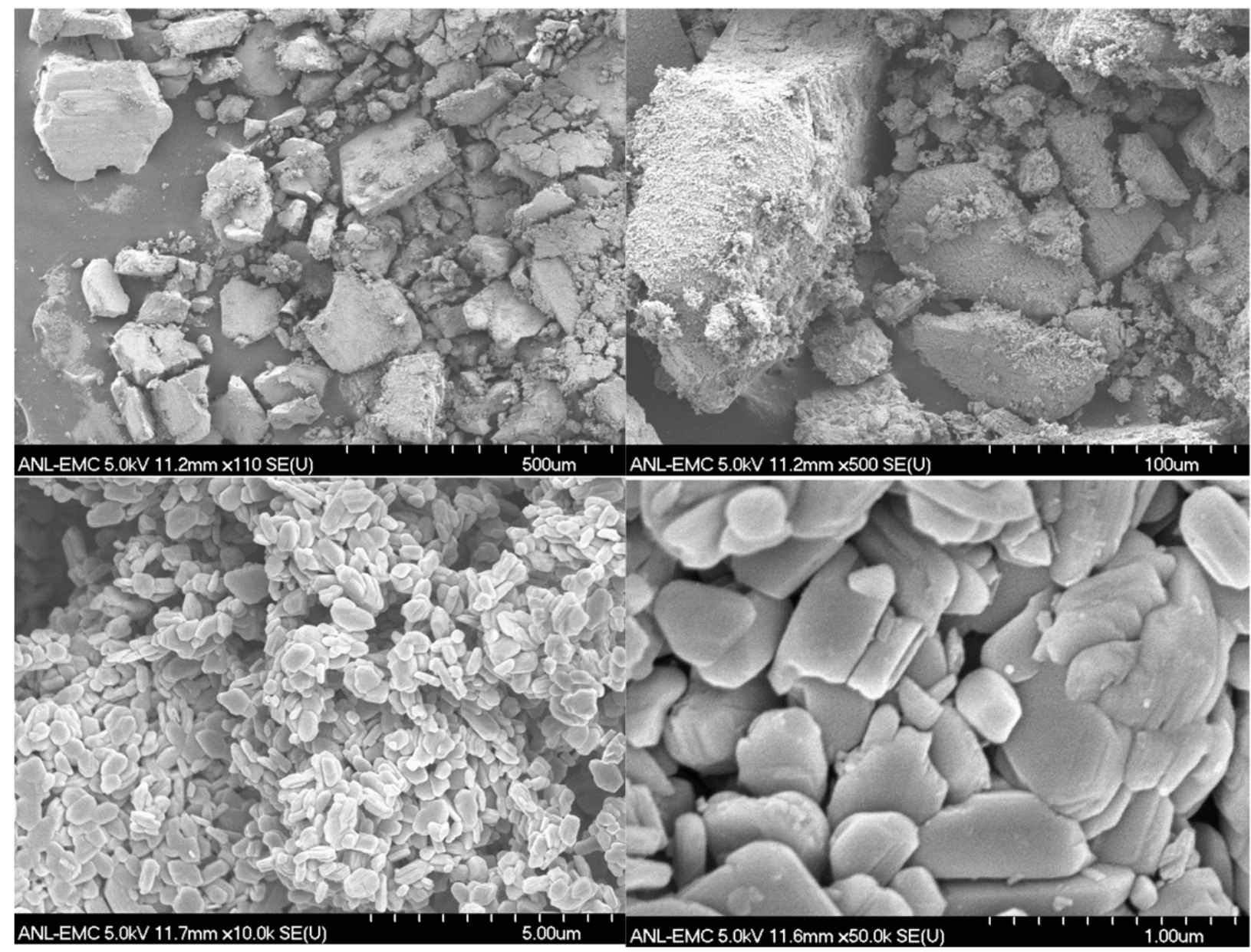

FIGURE 36 SEM Images of Sample 5 (NE) after Calcination at $500^{\circ} \mathrm{C}$ for 1 Hour. Large aggregates are present, but they consist of distinct micron and sub-micron particles of $\mathrm{MoO}_{3}$ (to be confirmed with XRD).

\subsection{CONCLUSION}

Based on this preliminary data and literature survey, we can draw the following conclusions and general comments:

1. While samples 1 and 5 had differing particle size distributions to begin with, both ended up with a similar distribution after calcination for extended periods. The heating rate on these tests was $50^{\circ} \mathrm{C} / \mathrm{min}$. This suggests that the initial PSD of the AHM does not necessarily affect the PSD of the resulting molybdenum oxide after calcination under specified conditions. However, ours was a crude test to assess chemical compatibility of the test materials. Further tests are needed for varying periods of time (from 30 min to several hours) and heating rates to fully establish this correlation. 
2. The calcination/TGA process has several variables that need to be accounted for:

a) Flow rate of air or static conditions: The temperature at which decomposition occurs is dependent on the partial pressure of the gas phase products, which, in turn, is dependent on the flow and heating rate. Use of low flow rates or static conditions have been observed to merge the various decomposition steps, i.e., the TGA does not exhibit distinct steps but a smooth continuous curve. Intermediate pathways where certain decomposition steps are not observed can also be achieved by using a combination of controlled flow and heating rates. Higher rates typically lead to distinct decomposition steps through stabilization of the intermediates.

b) Heating rate $\left(5-20^{\circ} \mathrm{C} / \mathrm{min}\right)$ : Variation in heating rate has been shown to change the shape of the TGA curve, often resulting in lowering of the temperature at which the different decomposition steps occur.

c) Time of calcination at particular temperature: Extended periods of calcination can result in sintering of the particles; needs to be explored further.

d) Composition of atmosphere: Decomposition in $\mathrm{O}_{2} / \mathrm{He} / \mathrm{N}_{2} / \mathrm{Ar}$ environments has been shown to change the TGA/DSC curves for the same material. This raises the question, Does the process need to be conducted in air only?

3. The calcination of AHM at various temperatures for 1 hour in air has decomposition steps confirmed by XRD (Table 10) [9]. Furthermore, the calcination process conducted at $375^{\circ} \mathrm{C}$ for 1 hour resulted in particles with 50-100 $\mu \mathrm{m}$ average size. XRD confirmed that this procedure results in a molybdenum oxyhydroxide material of mixed stoichiometry and not a true oxide. However, this could be a starting point for particle-size control experiments if mixed oxyhydroxide (e.g., $\mathrm{MoO}_{2.5}(\mathrm{OH})_{0.5}$ ) are suitable for the reduction process.

4. Given the relatively modest quantities of AHM and molybdenum oxide $(<50 \mathrm{~g})$, use of the laser diffraction method to obtain the PSD of the solid powders will be difficult, as it uses $100 \mathrm{~g}$ or more per sample per test. We propose the use of an image-based method to obtain PSD, i.e., software to quantify particle size based on optical or SEM images. 
TABLE 10 Calculated Values of Structural Parameters of AHM Calcined at Different Temperatures

\begin{tabular}{|c|c|c|c|c|}
\hline $\begin{array}{l}\text { Calcination tempera- } \\
\text { ture }\left({ }^{\circ} \mathrm{C}\right)\end{array}$ & $\begin{array}{l}\text { JCPDS } \\
\text { Card No. }\end{array}$ & Crystal structure molecular formula & Crystal phase & $\begin{array}{c}\text { Average crystallite } \\
\text { size }(\mathrm{nm})\end{array}$ \\
\hline $\mathrm{AHM}$ & $11-0071$ & {$\left[\mathrm{NH}_{4}\right]_{6}\left[\mathrm{Mo}_{7} \mathrm{O}_{24}\right] \cdot 4 \mathrm{H}_{2} \mathrm{O}$} & Monoclinic & 77 \\
\hline $50-75$ & $88-1326$ & $\begin{array}{l}{\left[\mathrm{NH}_{4}\right]_{4}\left(\mathrm{Mo}_{8} \mathrm{O}_{24.8}\left(\mathrm{O}_{2}\right)_{1.2}\right.} \\
\left.\quad\left(\mathrm{H}_{2} \mathrm{O}\right)_{2}\right)\left(\mathrm{H}_{2} \mathrm{O}\right)_{4}\end{array}$ & Monoclinic & 19 \\
\hline $100-200$ & $79-2084$ & {$\left[\mathrm{NH}_{4}\right]_{8} \mathrm{Mo}_{10} \mathrm{O}_{34}$} & Anorthic & 23 \\
\hline $225-275$ & $18-0117$ & {$\left[\mathrm{NH}_{4}\right]_{4} \mathrm{Mo}_{8} \mathrm{O}_{26}$} & Anorthic & 45 \\
\hline $325-475$ & $74-1648$ & $\mathrm{MoO}_{2.5}(\mathrm{OH})_{0.5}$ & Orthorhombic & $50-66$ \\
\hline 575 & $70-0615$ & $\mathrm{MoO}_{2.69}(\mathrm{OH})_{0.3}$ & Orthorhombic & 82 \\
\hline 675 & $35-0609$ & $\mathrm{MoO}_{3-x}$ & Orthorhombic & 98 \\
\hline
\end{tabular}

Further work will focus on determining the effects of

- Flow rate

- Heating rate and optimization with respect to flow rate

- Calcination temperature

- Aging (calcination for different times at a given temperature optimized)

Based on effects, we will make a global assessment on whether initial particle size of AHM affects the particle size of $\mathrm{MoO}_{3}$ after calcination.

\section{ACKNOWLEDGMENT}

Authors wish to thank Yifen Tsai (NE Division) for performing ICP-MS analysis, Jeff Fortner (NE Division) for providing some of the SEM images, Terry Cruse (NE Division) for performing XRD analyses. Work supported by the U.S. Department of Energy, NNSA's Material Management and Minimization office, under Contract DE-AC02-06CH11357. Argonne National Laboratory is operated for the U.S. Department of Energy by UChicago Argonne, LLC.

\section{REFERENCES}

[1] P. Tkac, G. F. Vandegrift, S. D. Nunn, J. Harvey, Recovery of Mo for Accelerator Production of Mo-99 Using $(\gamma, n)$ Reaction on Mo-100, Argonne National Laboratory Report ANL/CSE-13/45 (September, 2013).

[2] P. Tkac and G. F. Vandegrift, Optimization and Scale-up of Molybdenum-Recycle Process, Argonne National Laboratory Report ANL/CSE-14-33 (September 2014). 
[3] P. Tkac and G.F. Vandegrift, Recycle of enriched Mo targets for economic production of ${ }^{99} \mathrm{Mo} /{ }^{99 \mathrm{~m}} \mathrm{Tc}$ medical isotope without use of enriched uranium, J. Radioanal. Nucl.

Chem. 308: 205-212 (2016), doi 10.1007/s10967-015-4357-1.

[4] P. Tkac, D. A. Rotsch, M. A. Brown, V. Makarashvili, and G. F. Vandegrift, Chemical Processing Activities for ${ }^{99}$ Mo production by $(\gamma, n)$ and $(n, \gamma)$ reactions using enriched ${ }^{100}$ Mo and ${ }^{98}$ Mo targets, Topical Meeting on Molybdenum-99 Technological Development, August 31-September 3, 2015, Boston, MA.

[5] L.A. Bromley, Thermodynamic properties of strong electrolytes in aqueous solutions, AIChE J. 19: 313-320 (1973).

[6] R.A. Leonard, Solvent characterization using the dispersion number, Sep. Sci. Tech. 30: 1103-1122 (1995).

[7] B. Ravel and M. Newville, ATHENA, ARTEMIS, HEPHAESTUS: Data analysis for X-ray absorption spectroscopy using IFEFFIT, J. Synchrotron Radiat. 12: 537-541 (2005).

[8] K. Yokoi, N. Matsubayashi, T. Miyanaga, I. Watanabe, and S. Ikeda, Studies on the structure of molybdenum(VI) in acidic solution by XANES and EXAFS, Polyhedron 12: 911-914 (1993).

[9] A. Chithambararaj, D. Bhagya Mathi, N. Rajeswari Yogamalar, and A. Chandra Bose, Structural evolution and phase transition of $\left[\mathrm{NH}_{4}\right]_{6} \mathrm{Mo}_{7} \mathrm{O}_{24} \cdot 4 \mathrm{H}_{2} \mathrm{O}$ to $2 \mathrm{D}$ layered $\mathrm{MoO}_{3-\mathrm{x}}$, Mater. Res. Express 2(5): 055004 (2015). 



\section{Argonne}

\section{Nuclear Engineering Division}

Argonne National Laboratory

9700 South Cass Avenue, Bldg. 208

Argonne, IL 60439-4854

www.anl.gov

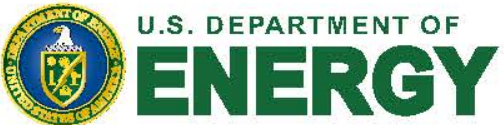

Argonne National Laboratory is a U.S. Department of Energy

laboratory managed by UChicago Argonne, LLC 